\title{
Article \\ Spatiotemporal Inversion and Mechanism Analysis of Surface Subsidence in Shanghai Area Based on Time-Series InSAR
}

\author{
Jiahao Li ${ }^{1}$, Lv Zhou ${ }^{1, *}$, Chao Ren ${ }^{1}{ }^{1}$, Lilong Liu ${ }^{1}$, Di Zhang ${ }^{2}{ }^{\circledR}$, Jun Ma $^{3}$ and Yujun Shi ${ }^{4}$ \\ 1 College of Geomatics and Geoinformation, Guilin University of Technology, Guilin 541006, China; \\ lijiahao@glut.edu.cn (J.L.); renchao@glut.edu.cn (C.R.); 1llong99@glut.edu.cn (L.L.) \\ 2 School of Geodesy and Geomatics, Wuhan University, Wuhan 430079, China; zhangdi@whu.edu.cn \\ 3 China Railway Siyuan Survey and Design Group Co., Ltd., Wuhan 430063, China; \\ yangzhiqou.student@sina.com \\ 4 Guangxi Deep Space Sail Engineering Survey and Design Co., Ltd., Nanning 530022, China; \\ 3182042041826@glut.edu.cn \\ * Correspondence: zhoulv@glut.edu.cn
}

Citation: Li, J.; Zhou, L.; Ren, C.; Liu, L.; Zhang, D.; Ma, J.; Shi, Y. Spatiotemporal Inversion and Mechanism Analysis of Surface Subsidence in Shanghai Area Based on Time-Series InSAR. Appl. Sci. 2021, 11, 7460. https://doi.org/10.3390/ app11167460

Academic Editor: Philippa J. Mason

Received: 22 May 2021

Accepted: 10 August 2021

Published: 13 August 2021

Publisher's Note: MDPI stays neutral with regard to jurisdictional claims in published maps and institutional affiliations.

Copyright: () 2021 by the authors. Licensee MDPI, Basel, Switzerland. This article is an open access article distributed under the terms and conditions of the Creative Commons Attribution (CC BY) license (https:// creativecommons.org/licenses/by/ $4.0 /)$.

\begin{abstract}
Abnormal surface subsidence has become a widespread geological problem being faced by cities. As a first-tier city in the world, there are problems such as unclear analysis of subsidence mechanism. Therefore, the monitoring of the Shanghai surface is particularly important. In this paper, the Sentinel-1A satellite SAR image data of 36 scenes covering Shanghai area from January 2018 to March 2020 were processed on the basis of time-series interferometry synthetic aperture radar technique. The subsidence rate field and accumulated surface subsidence in Shanghai area during the study period were obtained, and the spatial-temporal distribution characteristics of subsidence in the study area were discussed and analyzed from many different aspects. Moreover, the correlation between regional subsidence and geological structure, precipitation, urbanization, and other influencing factors were analyzed and established. Results show that the non-uniform subsidence in Shanghai area is clear, and those of the districts of eastern Songjiang, southern Jinshan, and Fengxian are more serious with a maximum subsidence rate of $-26.2 \mathrm{~mm} /$ year. After analyzing the causes of subsidence, the special foundation of soft soil in Shanghai area is determined as the main reason for the subsidence, and the uneven subsidence is mainly caused by the over-exploitation of groundwater, human activities, and the subsidence of soil layer. Through comparative analysis, factors, such as rainfall, groundwater, and urbanization process, have high correlation with surface subsidence.
\end{abstract}

Keywords: time-series InSAR; surface deformation; Shanghai area; spatial-temporal characteristics; Sentinel-1A

\section{Introduction}

As a serious geological disaster, surface subsidence will directly lead to major safety accidents, such as the collapsing of grounds and houses, which seriously threatens the safety of human life and property [1,2]. With the rapid development of urbanization in China, the surface non-tectonic deformation caused by human activities (e.g., natural resource exploitation and underground space engineering exploitation) has become a major geological disaster being faced by China [3]. According to the data, abnormal subsidence, which has caused great losses to people's life and property safety, has occurred in many areas in China (e.g., Beijing [4], Foshan [5]). Therefore, surface subsidence monitoring is particularly important. Traditional subsidence monitoring is mainly based on leveling and GNSS measurement [6,7], and these technologies are mainly based on the target of monitoring points and lack certain timeliness in the observation process $[8,9]$. For the monitoring of large-scale subsidence in some Chinese cities, the aforementioned technologies have the disadvantages of low spatial resolution, long period, and high cost $[10,11]$. 
In the 1960s, interferometry synthetic aperture radar (InSAR) technique achieved rapid development. This technique has been widely used in mine subsidence [12], volcano monitoring [13], landslide monitoring [14], earthquake [15], dam [16], and other aspects by virtue of its all-day, all-weather, and wide coverage. With the development of InSAR technique, differential interferometry synthetic aperture radar (DInSAR) technique was introduced. In 1989, Gabriel et al. [17] obtained the surface displacement of the Impirale Valley, California, USA by using DInSAR technique. However, this technique still has shortcomings (e.g., incoherence and atmospheric delay) that will directly lead to large errors in monitoring results. To solve the shortcomings of DInSAR, several time-series InSAR techniques have been proposed. In 2000, Ferretti et al. [18] proposed a persistent scatterer InSAR (PSInSAR) technique that works by calculating some persistent scatterer (PS) points during the study period. Then, the influence of atmospheric effect and incoherent factors is reduced. Unlike PSInSAR, the technique proposed by Berardino [19] in 2002, which was called small baseline subset InSAR (SBASInSAR), changed the point target modeling method into distributed target modeling analysis. In recent years, with the development of time-series InSAR technique, various time-series InSAR technologies (e.g., MTInSAR [20], TCPInSAR [21]) have emerged, and these time-series InSAR technologies all have good application prospect in surface subsidence monitoring. For example, Calof et al. [22] analyzed the driving factors of surface deformation in Kongya area by using SBASInSAR technique and combining the data of climate, strata, and land cover change. Zhou et al. [23] used SBASInSAR to investigate wide-area surface subsidence characteristics in Wuhan and analyzed and established the correlations between surface subsidence and urban construction, precipitation, industrial development, carbonate karstification, and water level changes in Yangtze River in Wuhan. Brunori et al. [24] used ENVISAT ASAR and RADARSAT-2 data to detect obvious subsidence in the northwest of Ciudad Guzmán. After field investigation, the feasibility of multi-temporal InSAR technique in surface subsidence was verified.

The subsidence monitoring of infrastructure in Shanghai has always been a research hotspot of scholars at home and abroad. Yang et al. [25] monitored Shanghai's reclamation area (Lingang New Area) based on time series InSAR by using various radar data and showed that the ground deformation after reclamation in Shanghai experienced three obvious stages: primary consolidation, slight rebound, and platform stage. Wang et al. [26] processed 49 TerraSAR-X images with TSInSAR technique, obtained the subsidence time series of viaduct in Shanghai, and analyzed it in combination with construction time, load, and other factors. Zhang et al. [27] extracted the average subsidence rate of coherent targets in line of sight by using the ALOSPALSAR data that covered the Shanghai area from 2007 to 2010 with the small baseline time series analysis method and verified the feasibility of SBAS technique in Shanghai by comparing with the leveling data. The obvious subsidence funnel in Shanghai area has been detected. Antonio et al. [28] used SBASInSAR technique to study the temporal evolution characteristics of surface deformation in Shanghai land reclamation area from 2007 to 2016. Combined with C-band and X-band data, the average cumulative deformation of Shanghai land reclamation from 2007 to 2016 reached $25 \mathrm{~cm}$. Lei et al. [29] obtained the deformation situation of Shanghai reclamation area in 2016 by using COSMS-SkyMed and Sentinel-1A data and obtained that the subsidence rate of Shanghai reclamation area was relatively high with a maximum subsidence rate reaching $30 \mathrm{~mm} /$ year. Qin et al. [30] used PSInSAR technique to monitor the main traffic infrastructure in Shanghai area and compared with the level data. They found that some traffic lines in Shanghai had serious subsidence and verified the feasibility of PSInSAR in subsidence monitoring in Shghai area. Zhao et al. [31] used InSAR technique to monitor Shanghai Lupu Bridge and verified the feasibility of PSInSAR technique in deformation monitoring of a single building. The subsidence monitoring in Shanghai is mainly focused on the local monitoring of infrastructure and other aspects. Studies on the large-scale surface subsidence monitoring in Shanghai are relatively few, and discussions on the subsidence mechanism are lacking. Moreover, the research data are mostly from 5 years ago, thereby lacking certain timeliness. 
In this paper, we first processed and analyzed the Sentinel-1A image data of 36 scenes based on PSInSAR technique, and then obtained the deformation rate field from January 2018 to March 2020 in Shanghai. Second, we investigated the surface subsidence spatialtemporal characteristics in Shanghai area in detail. Finally, the driving factors of subsidence were analyzed in combination with urbanization construction, groundwater level change, rainfall, and other factors in Shanghai. These factors provide scientific data support for the surface subsidence prevention and control in Shanghai area.

\section{Methodology}

Aiming at the problems of interference incoherence and atmospheric delay error that exists in DInSAR technique, PSInSAR technique can reduce the influence of interference incoherence and atmospheric delay error on the calculation results effectively. Unlike DInSAR technique, PSInSAR focuses on the use of SAR image sequences acquired from the same area during a certain period. First, according to the scattering characteristics of ground objects and statistical analysis method, the permanent scatterers with high correlation in time series in the study area are detected. Second, based on the phase time series of these specific targets, modeling and analysis are carried out to obtain high-precision deformation measurement results. The main steps are detailed as follows [32-34]:

(1) Assume the N+1 SAR images covering the same area. Arrange the SAR images according to the time series. Calculate the temporal baseline, spatial baseline, and doppler centroid frequency difference between the images. Establish the relevant model according to the three aforementioned factors to select the reference image.

$$
\rho^{m}=\frac{1}{K} \sum_{k-1}^{k}\left[\left(1-\frac{B_{\perp}^{k, m}}{B_{c}}\right) \times\left(1-\frac{T^{k, m}}{T_{\mathcal{C}}}\right) \times\left(1-\frac{B_{D C}^{k, m}}{f_{\mathcal{C}}}\right)\right]
$$

where $\rho^{m}$ is the comprehensive correlation coefficient of an interference pair; $B_{\perp}^{k, m}, T^{k, m}$, and $B_{D C}^{k, m}$ are the perpendicular baseline, temporal baseline, and Doppler centroid frequency difference between interference images $k$ and $m$, respectively. The critical conditions of the aforementioned parameters are $B_{\mathcal{c}}, T_{\mathcal{c}}$, and $f_{c}$, respectively. The image with the maximum value is the reference image to select the optimal reference image.

(2) After calculation, the image on 29 June 2019 was selected as the reference image in this paper. All the secondary images were registered to the reference image, and $\mathrm{N}$ interference pairs were generated after differential interference processing. The spatialtemporal baseline distribution is shown in Figure 1, and the specific spatial-temporal baseline distribution parameters of Sentinel-1A data are listed in Table 1.

(3) The amplitude deviation index method was used to select the high-amplitude value as the candidate PS point according to the strong reflection characteristics of PS points. The algorithm of amplitude deviation index is shown in (2). The interference phase information contained in the candidate PS points can be expressed as Equation $(3)[35,36]$ :

$$
\begin{gathered}
D=\frac{\sigma_{i}}{m_{i}} \\
\phi=\phi_{\text {ref }}+\phi_{\text {def }}+\phi_{\text {topo }}+\phi_{a t m}+\phi_{\text {noi }}
\end{gathered}
$$

where $D$ is the amplitude deviation index, $\sigma_{i}$ is the amplitude standard deviation of the images with time series, and $m_{i}$ is the mean amplitude of the time series image. In Equation (3), $\phi$ is the interference phase; $\phi_{\text {ref }}$ represents the flat-earth phase; $\phi_{\text {def }}$ refers to the surface deformation phase; $\phi_{\text {topo }}$ corresponds to the phase caused by topographic relief; $\phi_{a t m}$ denotes atmospheric phase error; and $\phi_{n o i}$ depicts the rando//m noise phases (e.g., orbital errors, thermal noise, and spatial decorrelation). Among them, $\phi_{\text {ref }}$ can be eliminated by precise orbit data, $\phi_{\text {topo }}$ can be eliminated by external DEM. 

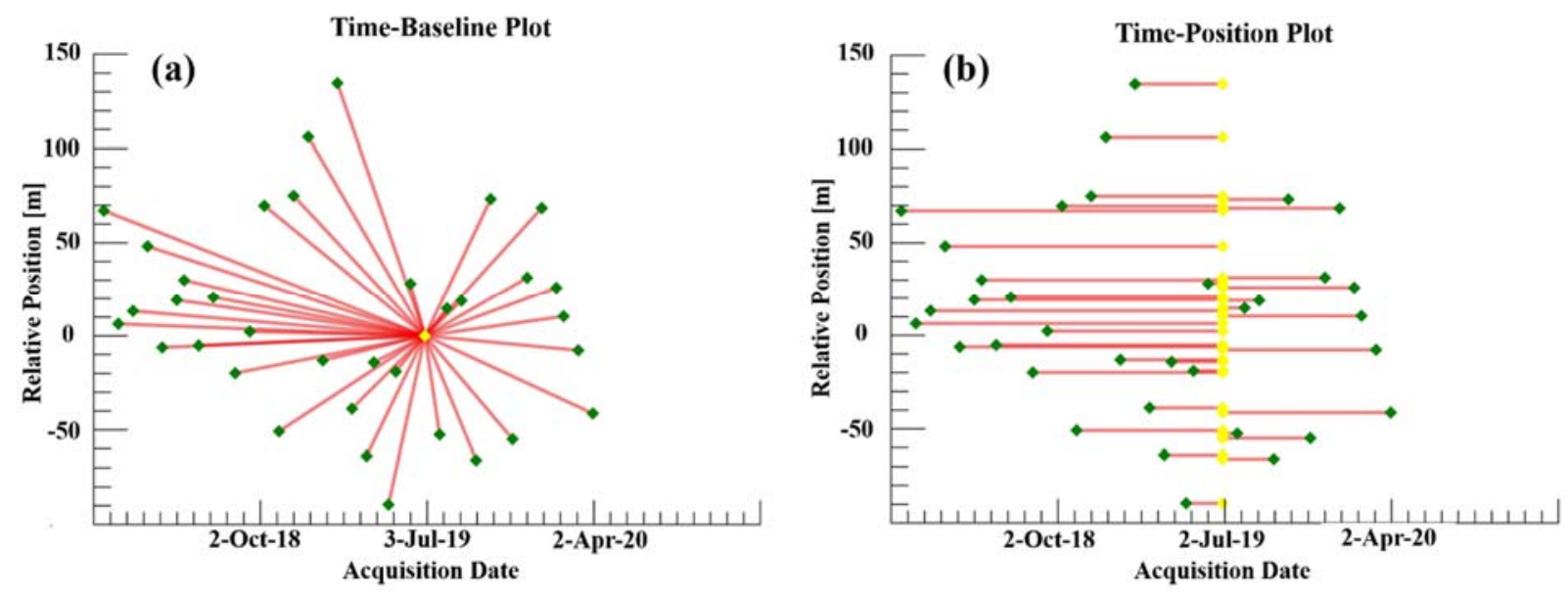

Figure 1. (a) Time-position of Sentinel-1A image interferometric pairs; and (b) time-baseline of image interferometric pairs. The red lines depict interferometric pairs. The yellow and green diamonds correspond to the reference image and secondary images, respectively.

Table 1. Spatial-temporal baseline distribution parameters of Sentinel-1A.

\begin{tabular}{|c|c|c|c|c|c|c|c|}
\hline $\begin{array}{c}\text { Serial } \\
\text { Number }\end{array}$ & Image & $\begin{array}{c}\text { Spatial } \\
\text { Baseline/m }\end{array}$ & $\begin{array}{c}\text { Temporal } \\
\text { Baseline/d }\end{array}$ & $\begin{array}{c}\text { Serial } \\
\text { Number }\end{array}$ & Image & $\begin{array}{c}\text { Spatial } \\
\text { Baseline/m }\end{array}$ & $\begin{array}{c}\text { Temporal } \\
\text { Baseline/d }\end{array}$ \\
\hline 1 & 17 January 2018 & 67.09 & -528 & 19 & 25 March 2019 & -63.73 & -96 \\
\hline 2 & 10 February 2018 & 6.41 & -504 & 20 & 6 April 2019 & -14.19 & -84 \\
\hline 3 & 6 March 2018 & 13.28 & -480 & 21 & 30 April 2019 & -89.44 & -60 \\
\hline 4 & 30 March 2018 & 48.10 & -456 & 22 & 12 May 2019 & -19.04 & -48 \\
\hline 5 & 23 April 2018 & -6.24 & -432 & 23 & 5 June 2019 & 28.04 & -24 \\
\hline 6 & 17 May 2018 & 19.20 & -408 & 24 & 29 June 2019 & 0 & 0 \\
\hline 7 & 29 May 2018 & 29.99 & -396 & 25 & 23 July 2019 & -52.51 & 24 \\
\hline 8 & 22 June 2018 & -5.17 & -372 & 26 & 4 August 2019 & 14.74 & 36 \\
\hline 9 & 16 July 2018 & 20.67 & -348 & 27 & 28 August 2019 & 18.82 & 60 \\
\hline 10 & 21 August 2018 & -19.90 & -312 & 28 & 21 September 2019 & -65.90 & 84 \\
\hline 11 & 14 September 2018 & 2.30 & -288 & 29 & 15 October 2019 & 73.27 & 108 \\
\hline 12 & 8 October 2018 & 69.68 & -264 & 30 & 20 November 2019 & -54.98 & 144 \\
\hline 13 & 1 November 2018 & -50.82 & -240 & 31 & 14 December 2019 & 31.26 & 168 \\
\hline 14 & 25 November 2018 & 75.00 & -216 & 32 & 7 January 2020 & 68.47 & 192 \\
\hline 15 & 19 December 2018 & 106.11 & -192 & 33 & 31 January 2020 & 25.88 & 216 \\
\hline 16 & 12 January 2019 & -13.09 & -168 & 34 & 12 February 2020 & 10.44 & 228 \\
\hline 17 & 5 February 2019 & 134.60 & -144 & 35 & 7 March 2020 & -7.76 & 252 \\
\hline 18 & 1 March 2019 & -38.77 & -120 & 36 & 31 March 2020 & -41.35 & 276 \\
\hline
\end{tabular}

(4) After separating the linear deformation and elevation error from $\phi$ using the correlation characteristics of atmospheric phase with low correlation in time and high correlation in space, the high-pass filtering in time and low-pass filtering in space are used to obtain the estimated values of atmospheric phase and nonlinear deformation in each scene of the differential interferogram.

$$
\begin{gathered}
\Delta \phi_{\text {diff }}=\phi_{\text {def }}+\phi_{\text {atm }}+\phi_{\text {noi }} \\
\phi_{\text {def }}=\phi_{\text {lin }}+\phi_{\text {non }}
\end{gathered}
$$

where $\Delta \phi_{\text {diff }}$ represents the interferometric phase after removing the flat-earth and topographic phases; and $\phi_{\text {lin }}$ and $\phi_{\text {non }}$ denote the linear and nonlinear surface deformation phases, respectively. $\phi_{d e f}$ refers to the deformation phase.

(5) The deformation phase can be obtained by adding the nonlinear and linear deformation, and then the deformation information in the study area can be solved. 


\section{Study Area and Data \\ 3.1. Study Area}

Shanghai $\left(120^{\circ} 52^{\prime} \mathrm{E}-122^{\circ} 12^{\prime} \mathrm{E}, 30^{\circ} 40^{\prime} \mathrm{N}-31^{\circ} 53^{\prime} \mathrm{N}\right)$ is located in the easternmost part of the Yangtze River Delta in China. The average altitude is approximately $4 \mathrm{~m}$ above sea level. It is at the confluence of the Yangtze River and the Huangpu River. The place borders the Yangtze River to the north and the East China Sea to the east. Shanghai is a typical soft soil area with complex geological structure and large pore ratio. A large number of infrastructure construction can easily lead to abnormal subsidence in the area. Many faults exist in the Shanghai area, but these faults are mainly the early and middle Pleistocene faults and are classified as inactive. Therefore, the geological structure of this area is relatively stable, and it is not easy for major structural changes to occur.

Shanghai is one of the largest industrial bases in China. Many scientific research and production bases of light and heavy industrial products are located in Shanghai. Shanghai has a population of 24.28 million, thereby making it the second most populous city in China by 2019. The geographical location of the study area in this paper is represented by the area in the red rectangle in Figure 2a, which contains most of Shanghai. Figure $2 b$ shows the backscattering intensity image of Sentinel-1A SAR image that covers the study area, and the measures in east-west and south-north directions are approximately $79.46 \mathrm{~km}$ and $78.43 \mathrm{~km}$, respectively. The background shows the Google image that covers Shanghai area.
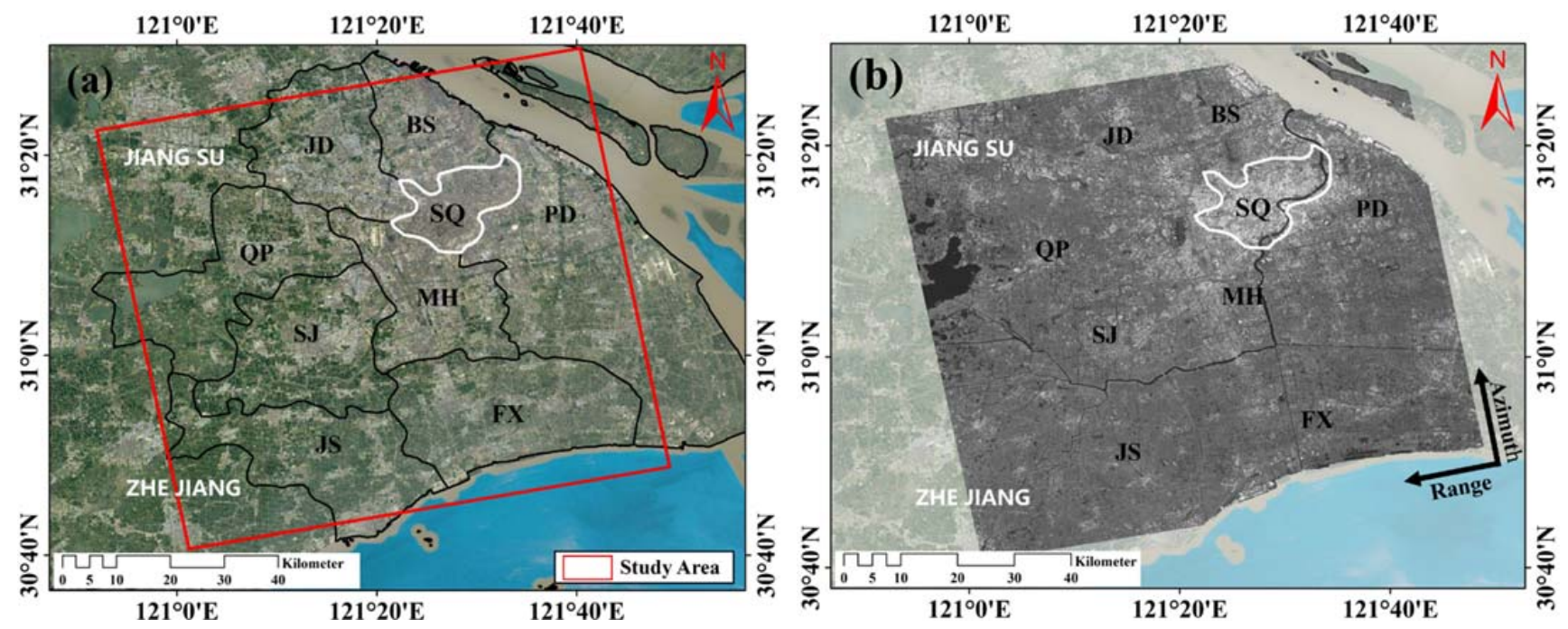

Figure 2. (a) The black area is the municipal area of Shanghai, including Baoshan (BS), Jiading (JD), Qingpu (QP), Minhang (MH), Pudong New Area (PD), Songjiang (SJ), Jinshan (JS), and Fengxian (FX); and (b) Sentinel-1A image intensity map of the study area. The red rectangle depicts the study area of this paper. The white line corresponds to the urban area of Shanghai (SQ); The black lines represent the division of Shanghai.

Due to its geographical location, Shanghai enjoys convenient transportation, advanced culture, and rapid industrial development. In recent years, many infrastructure and rail transits have been constructed in Shanghai, thereby signifying an uneven subsidence phenomenon. Shanghai has a subtropical monsoon climate with abundant rainfall, and the typical rainy season occurs in September of each year, with approximately $60 \%$ of the annual precipitation. The rainfall change has a great impact on regional surface subsidence, and the seasonal variation of subsidence is evident. To alleviate the excessive groundwater in the region, the Shanghai municipal government adopts tap water recharge to maintain the basic balance of groundwater. It has also become one of the measures to alleviate the surface subsidence. 


\subsection{Data}

The 36 ascending SAR images used in this paper are from Sentinel-1A launched by the European Space Agency (ESA) (https:/ / scihub.copernicus.eu/dhus/\#/home, 20 May 2020), the satellite carries $C$-band synthetic aperture radar antenna with a 12-day revisit cycle. It can monitor the ground micro-deformation effectively. The time span of the 36 SAR images are from January 2018 to March 2020. The incidence angle of the image center is $36.6^{\circ}$. All of the SAR images are in $\mathrm{VH}$ polarization with a resolution of $1.2 \mathrm{~m}$ in range and $13.9 \mathrm{~m}$ in azimuth. Specific image parameters are illustrated in Table 2. The three arc-second Shuttle Radar Topography Mission (SRTM) DEM provided by the National Aeronautics and Space Administration (NASA) (http://srtm.csi.cgiar.org/srtmdata, 2 June 2020) was used to remove the topographic phase. We adopted the ESA-released precise orbit data (https: / / qc.sentinel1.eo.esa.int/aux_poeorb, 22 June 2020) to execute orbital refinement and phase re-flattening for all interferometric pairs. The rainfall data were provided by China National Meteorological Science Data Center, the groundwater level and the position of water level monitoring wells were provided by Shanghai Geological Data Information Sharing Platform, and the night-light remote sensing data were the monthly composite product of NPP-VIIRS. The above data were used to analyze the mechanisms of surface subsidence in the study area. The spatial distribution of data is shown in Figure 3.

Table 2. Specific parameters of Sentinel-1A SAR images.

\begin{tabular}{cc}
\hline Parameters & Description \\
\hline Imaging mode & IW \\
Data type & SLC \\
Band & $\mathrm{C}(5.63 \mathrm{~cm})$ \\
Revisit cycle & 12 days \\
Polarization mode & VH \\
Time span & January 2018-March 2020 \\
Orbit direction & Ascending \\
Central incidence angle on the test site & $36.6^{\circ}$ \\
Range resolution & $1.2 \mathrm{~m}$ \\
Azimuth resolution & $13.9 \mathrm{~m}$ \\
\hline
\end{tabular}

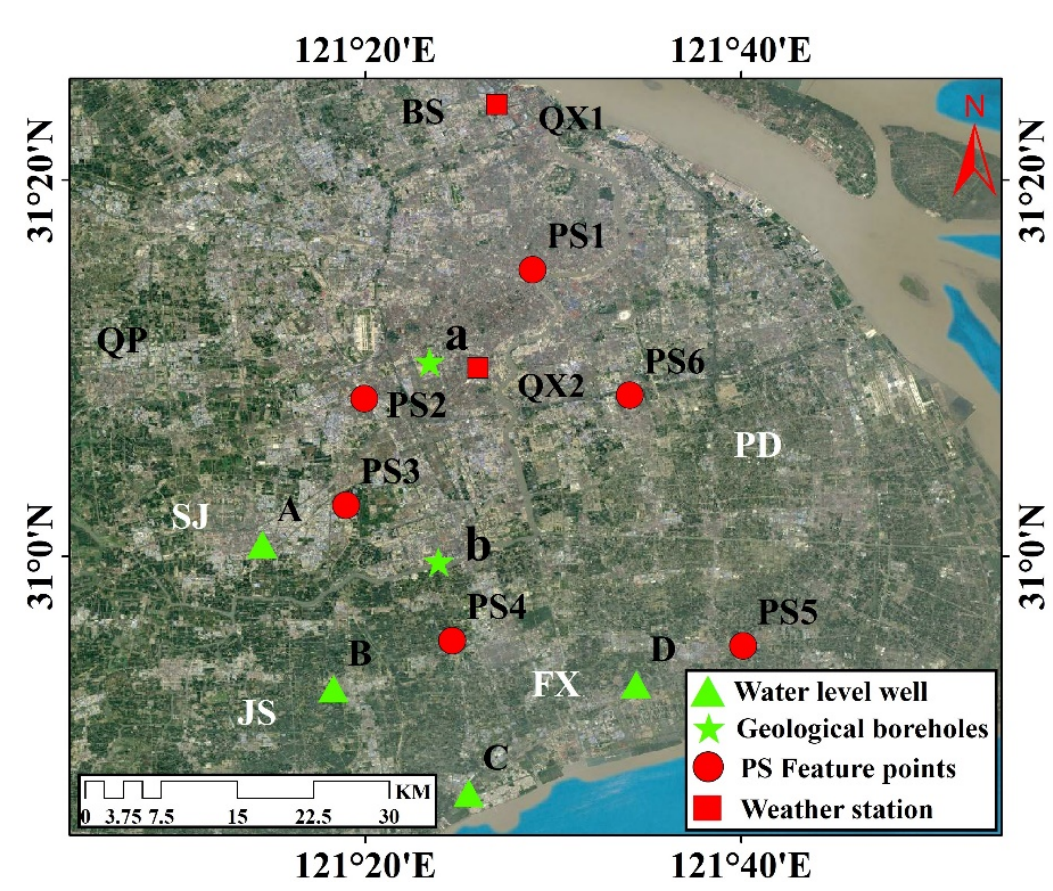

Figure 3. Distribution of data points. The green triangles depict the water level of wells, green pentagrams denote the geological boreholes, red circles represent the PS feature points, and the red squares denote the weather stations. 


\section{Results}

\subsection{Results and Analysis of Subsidence Rate}

After processing the 36 Sentinel-1A SAR images, the subsidence rate field and accumulated subsidence in Shanghai from January 2018 to March 2020 were obtained. Figure 4 shows the surface subsidence rate map in Shanghai area derived by PSInSAR (the positive values indicate surface uplift, and the negative values represents surface subsidence), and the map is superimposed on a Google Earth image of Shanghai acquired in 2020.

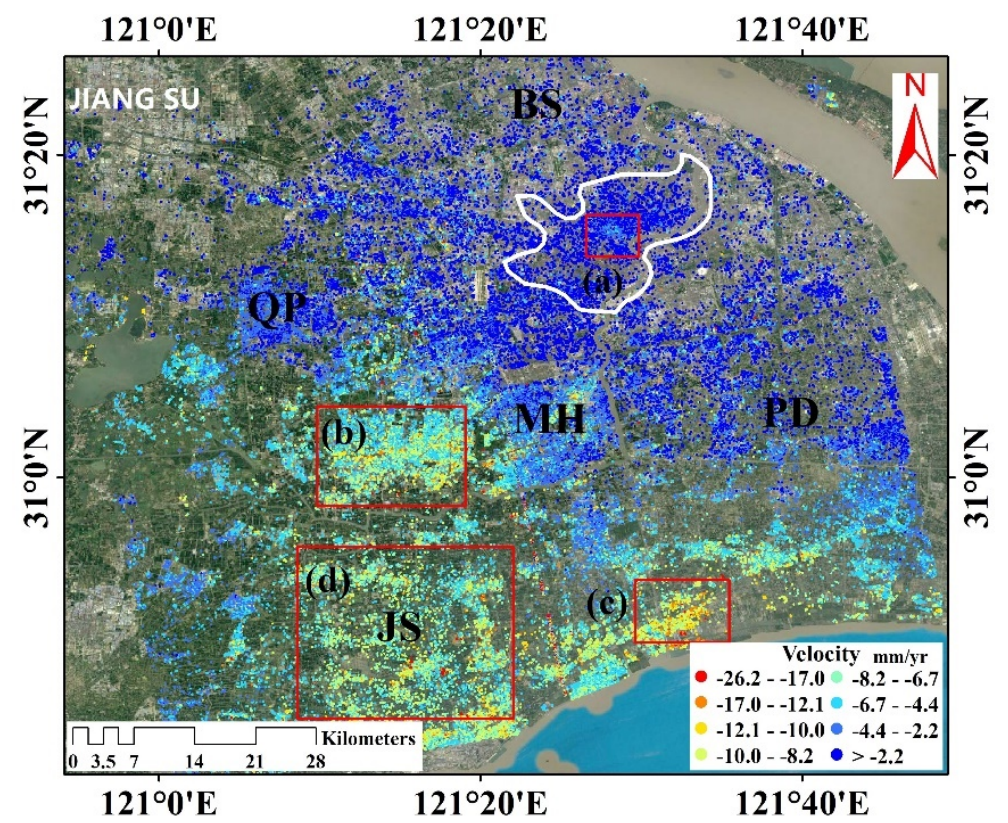

Figure 4. Surface subsidence rate map in the study area obtained by PSInSAR; The white curve area denotes the urban area of Shanghai (SQ); The red rectangles depict characteristic areas.

The subsidence is relatively stable in most areas of Shanghai. However, the uneven subsidence phenomenon is obvious. Region a is located in the urban area of Shanghai. The subsidence in this region is relatively stable and without obvious subsidence. The main subsidence areas in Shanghai include Region b (SJ), Region c (FX), and Region d (JS). Large-scale subsidence occurs in the three regions. The subsidence range of Region $\mathrm{b}$ presents an expanding trend, and the subsidence rates range from $-15.0 \mathrm{~mm} /$ year to $5 \mathrm{~mm} /$ year. The overall subsidence rate in Region $\mathrm{d}$ is relatively high, which are between $-25 \mathrm{~mm} /$ year and $6 \mathrm{~mm} /$ year. Many large industrial areas, such as Jinfengyuan Paper (JFYP), Yadong Petrochemical (YDP), Shanghai Paimilei Industrial Park (SPIP), are found in Region c. Moreover, this region is the most serious subsidence area in Shanghai with multiple significant subsidence funnels.

Region a is the main urban area of Shanghai. As shown in the subsidence rate map, the subsidence rate in this area is around $-3 \mathrm{~mm} /$ year, and the subsidence is relatively stable without significant subsidence. According to the "Shanghai City Master Plan (1999-2020)" released by the Shanghai Municipal Urban Planning Administration, Shanghai has made strict restrictions on the population and urban construction land in the main urban area. Moreover, the central urban area has been built earlier, in which the subsidence has tended to stabilize.

Region b is located in Songjiang District, Shanghai. According to the "Shanghai Songjiang District Master Plan and Land Use Master Plan (2017-2035)" published by the People's Government of Songjiang District of Shanghai, Songjiang District will adhere to the development trend of combining multiple towns and Songjiang New City as the center. Under the condition of ensuring the steady growth of the regional ecological area, the construction of urban infrastructure and manufacturing factories should be strengthened. 
These conditions have led to the rapid development of the industry in Songjiang District from 2017 to 2020. Population data show that by 2020, the region's permanent population reached 1582,400. Industrial and domestic water mainly come from the exploitation of underground water. In Section 5.3, the relationship between the surface subsidence and the change of the water table will be further discussed.

\subsection{Results and Analysis of Subsidence Time Series}

Figure 5 shows the cumulative subsidence time series in Shanghai from 2018 to 2020. During the study period, the maximum cumulative subsidence in Shanghai is $-68 \mathrm{~mm}$, and it is located in Region c in the south of Fengxian District. As a whole, no large-scale subsidence is observed in Shanghai area during 2018-2019, and the subsidence has been slow. However, after 2019, the subsidence in Shanghai has shown an accelerating trend, which may be affected by the regional rainfall and the rainy season in the lower reaches of the Yangtze River.
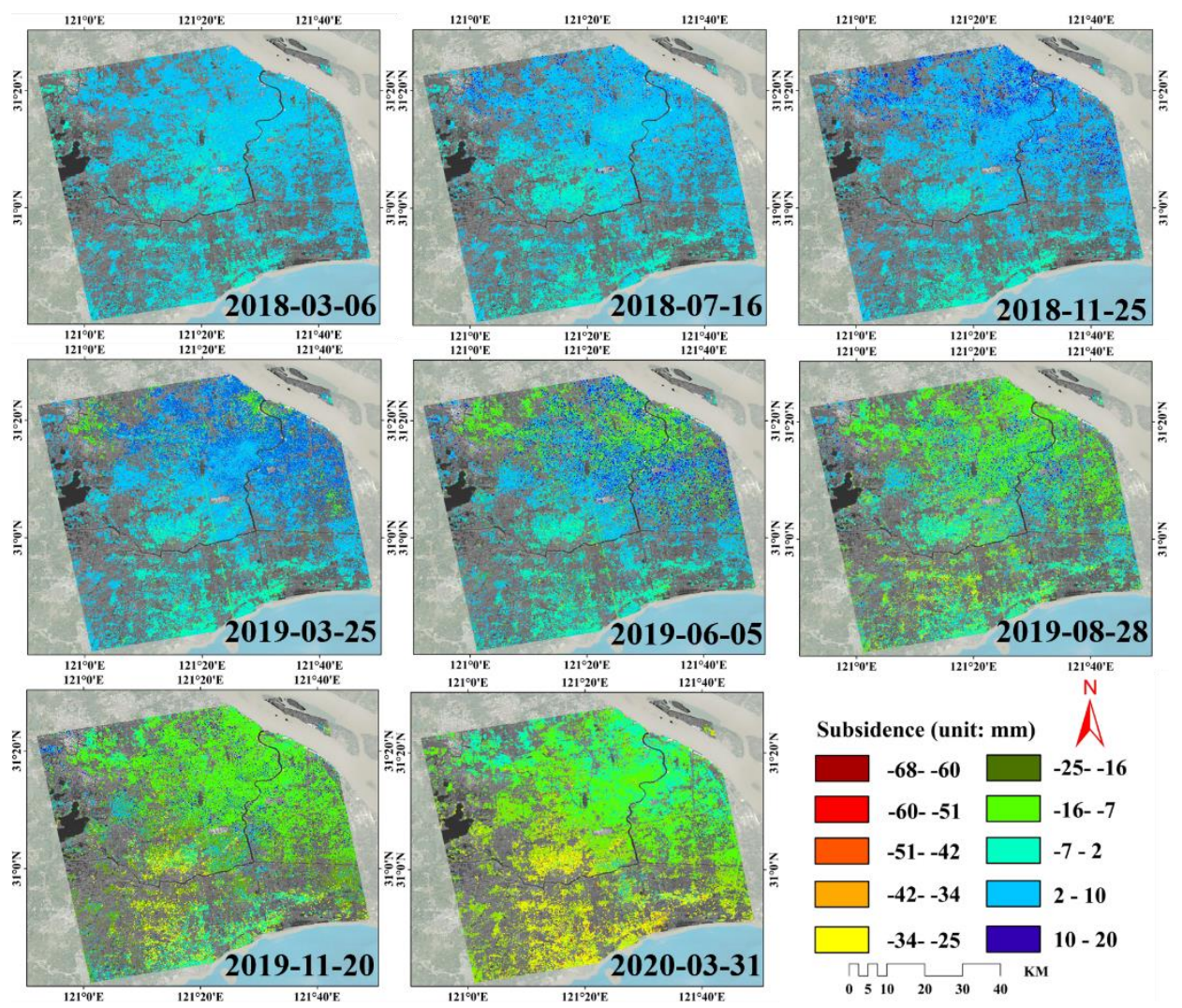

Figure 5. Time series of accumulated subsidence in the study area from 2018 to 2020.

The subsidence in the northern part of Shanghai is relatively stable, and the accumulated subsidence range from $-10 \mathrm{~mm}$ to $20 \mathrm{~mm}$. Figure 5 presents that the subsidence in the northern part of Shanghai has been showing a slow subsidence trend without serious large-scale subsidence. In the middle part of Shanghai, the subsidence near Songiiang District is more serious, with the maximum accumulated subsidence reaching $-44 \mathrm{~mm}$. In the cumulative time series, the Songjiang District has been showing a downward trend, with a relatively stable settlement range but without any obvious diffusion trend. Jinshan District and Fengxian District in the south of Shanghai have the most obvious subsidence phenomenon, the subsidence amount is gradually increasing, and the subsidence area is gradually expanding. 


\subsection{Accuracy Evaluation of Time Series InSAR Results}

To assess the internal precision of the subsidence rate field extracted from Sentinel-1A SAR data processed by PSInSAR technique in Shanghai area, the standard deviation of the obtained subsidence rate is statistically analyzed in this section. According to the statistical results, 637,213 PS points were detected in the study area, $98 \%$ of PS points standard deviation are less than $1 \mathrm{~mm} /$ year, and the maximum standard deviation reaches $2.28 \mathrm{~mm} /$ year. In conclusion, PSInSAR technique exhibits high reliability and stability in monitoring surface subsidence in Shanghai area.

\section{Discussion}

\subsection{Time Series Analysis of Feature Points}

To analyze the temporal and spatial characteristics of subsidence distribution in Shanghai better, this section randomly selects six feature points (i.e., PS1-PS6) scattered in different areas of Shanghai for specific analysis. The specific distribution of feature points is shown in Figure 3, and the accumulated subsidence amount of six time series points is shown in Figure 6.

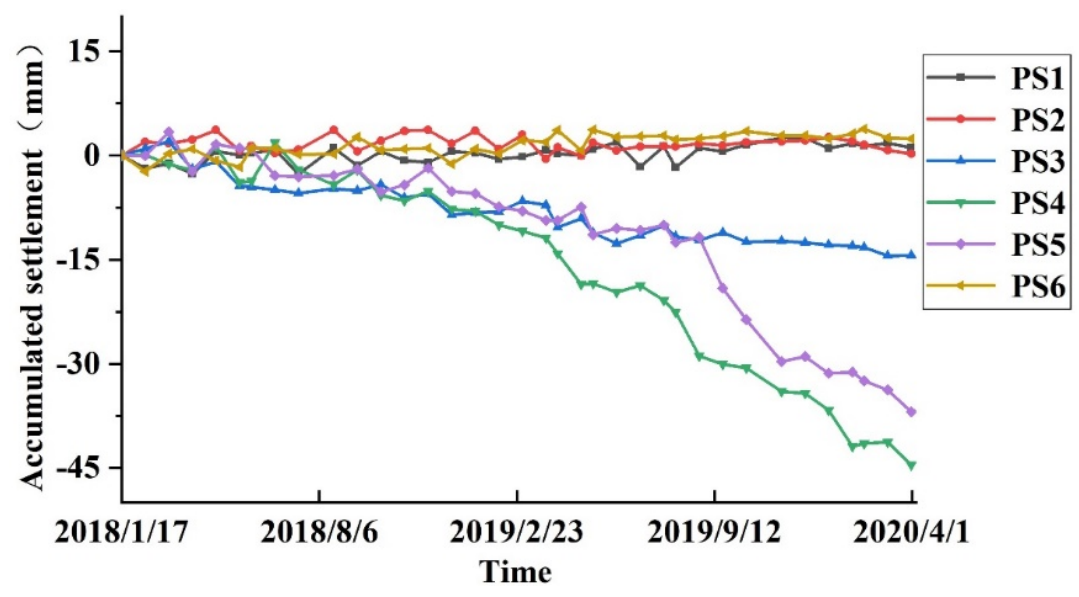

Figure 6. Subsidence time series with respect to PS points labeled as PS1-PS6 in Figure 3.

PS1 is located in the vicinity of Sichuan North Road Park in Hongkou District, which was constructed earlier. The area is the location of the old city of Shanghai, and the subsidence here has basically stabilized. Therefore, the subsidence of PS1 is relatively stable during the study period, and no excessive subsidence phenomenon occurred.

PS2 is located near Xinglian Central Village, Jiuting Town, Songjiang District. In the subsidence area, the subsidence fluctuation is relatively small, and no obvious subsidence phenomenon occurred.

PS3 is located near the Pailoutou Building in Minhang District. The point shows a slow subsidence trend with an accumulated subsidence of $-14.4 \mathrm{~mm}$. Many industrial parks and factories are found in this area. Moreover, the industrial water is extracted from groundwater, which is the main cause of subsidence.

PS4 is located near Fei Shangwangiia in Fengxian District. There are a large number of large factories such as aluminum products and machinery parts production plants. Industrial production and industrial water using become one of the main factors for subsidence. The maximum accumulated subsidence in this area is $-44.6 \mathrm{~mm}$, and the subsidence phenomenon is more obvious.

PS5 is located near Shanghai Keen Machinery Manufacturing, Fengxian District. The surface of this area shows a continuous subsidence trend, and many machinery part production factories are found in this area, which becomes one of the main reasons for the subsidence in this area.

PS6 is located near Kangqiao Peninsula in Pudong, and the subsidence in this area is basically stable without obvious subsidence. 
In general, the temporal and spatial inhomogeneity of subsidence in Shanghai is obvious, which shows uplift in the east and decline in the west and uplift in the north and decline in the south. The surface subsidence in Shanghai is nonlinear because of the over-exploitation of groundwater in the region.

\subsection{Influence of Regional Stratigraphic Structure on Surface Subsidence}

Shanghai, which is located in the southeast front of the estuary of the Yangtze River Delta, is one of the world's famous mega cities located on soft soil. It belongs to the coastal plain landform type, and its geological age is Holocene Q4 and Upper Pleistocene Q3. As the longest river in Asia, the main stream of the Yangtze River flows through 11 provinces and cities before reaching the Huangpu River in Shanghai and entering the sea. The size of soil particles carried by the Yangtze River changed significantly in the process of flowing through various regions. Shanghai has suffered from the long-term impact of the Yangtze River estuary, and a huge amount of land was lost every year. According to the "Shanghai Water Resources Bulletin in 2019," the total soil erosion area of Shanghai in 2019 is 2.89 square kilometers, which accounts for $0.05 \%$ of the total land area of the city. Moreover, the sediment carried by the Yangtze River to Shanghai is mainly concentrated in particles of $0.005 \mathrm{~mm}$ to $0.075 \mathrm{~mm}$. The particles, which are typical clay particles and accumulate to form silty soil, are relatively small.

To analyze the influence of geological structure in Shanghai on regional subsidence better, we obtained the geological data of two Quaternary Geological Boreholes (the green pentagram in Figure 3) in Shanghai area. Borehole a is located near Hongqiao Central Primary School, Minhang District, Shanghai, with a final depth of $300.44 \mathrm{~m}$. The borehole $\mathrm{b}$ is located in the south of Yuanjiang Road, Zhongchun Road, Beiqiao Town, Minhang District, Shanghai, with a final depth of $336.29 \mathrm{~m}$.

In terms of Quaternary geology, the soil layer in Shanghai is evenly distributed. The upper layer is silty powdery clay, and the lower layer is silty clay, which together constitute the typical soft soil in Shanghai. In the soft soil layer, the soil moisture content is higher, and the hardness is relatively soft. Geological layers in Shanghai are mainly divided into artificial filled soil, cohesive soil, silty clay, and powder silt soil. The specific soil layer distribution of boreholes a and b are shown in Figure 7. The soil layer in Shanghai is mostly composed of soft clay soil, which has poor engineering geological properties, such as high water content, large void, and high compressibility. According to existing research, Shanghai is dominated by clay. The natural pore ratio of the soil is $0.7-1.4$, the natural water content is between $26.9-49.7 \%$, and the compression modulus of the soil is between $2.56-6.43 / \mathrm{Mpa}($ Es $0.1-0.2)[37,38]$. There exists a certain linear relationship among the three, which reflects the characteristics of high-water content, large voids and high compressibility of the soils in Shanghai. With the development of surface urbanization and excessive development of urban underground space, the soil pressure in Shanghai is increasing. In addition, due to the characteristics of the soil, the bearing capacity of the area is low, and the overall subsidence and uneven subsidence are prone to occur [39,40]. Under the influence of geology and underlying structure, excessive subsidence occurred at the construction site of Shanghai Rail Transit Line 16 in 2011, which resulted in collapse. In 2012, the construction site of Metro Line 12 collapsed and have caused serious harm to people's property and safety. In Shanghai, the soft soil layer composed of soft clay soil is relatively thick. In terms of engineering construction, subway tunnels in Shanghai area generally pass through the soft soil layer, and viaducts and highways are all affected by the soft soil layer, thereby resulting in subsidence. Therefore, the influence of soft soil layer on regional engineering construction and daily maintenance cannot be ignored. 


\begin{tabular}{|c|c|}
\hline & Grey silty clay $(24.00 \mathrm{~m})$ \\
\hline & Grayish yellow fine sand $(90.00 \mathrm{~m})$ \\
\hline \multicolumn{2}{|r|}{ Gray white coarse sand $(99.00 \mathrm{~m})$} \\
\hline \multicolumn{2}{|r|}{ Frey silfy elay $(1230000)$, } \\
\hline \multicolumn{2}{|r|}{ Grey fine sand $(134.80 \mathrm{~m})$} \\
\hline \multicolumn{2}{|r|}{ Andesite (236.25m) } \\
\hline & Mudstone (300.44m) \\
\hline
\end{tabular}

(a)

\begin{tabular}{|c|}
\hline Muddy clay $(18.00 \mathrm{~m})$ \\
\hline Silty sand and silty clay $(44.97 \mathrm{~m})$ \\
\hline Mud With sand $(96.2 \mathrm{~m})$ \\
\hline Silty sand and silty clay $(124.35 \mathrm{~m})$ \\
\hline Yellow clay $(195.00 \mathrm{~m})$ \\
\hline Clay $(237.00 \mathrm{~m})$ \\
\hline Mudstone $(335.00 \mathrm{~m})$ \\
\hline
\end{tabular}

(b)

Figure 7. Shanghai geological planing surface map. (Borehole (a) is shown on the left, borehole (b) is shown on the right, and red number indicates the bottom burial depth. The color is Quaternary Geology and the gray is deep bedrock).

In terms of deep bedrock, the bedrock borehole data used in this paper is about $300 \mathrm{~m}$ below ground. As Shanghai is a deltaic impact plain, the deep bedrock is dominated by mudstone and mud-intercalated sand, and the composition is dominated by feldspar, quartz and small gravels. The bedrock core of this type is harder, while the water content in the mud is still larger. The bedrock is hard plastic and the mud with high water content is still much more, which also reflects, to some extent, the poor geological structure of Shanghai and the importance of continuous monitoring of the subsidence phenomenon in Shanghai.

In terms of tectonic forces, there are no concentrated and large geological faults in Shanghai, and the regional geological structure is relatively stable. The effects of tectonic forces are mostly on a large time scale range, and the study span in this paper is relatively small. The subsidence in Shanghai is dominantly affected by groundwater and urban development, so the natural subsidence caused by tectonic forces in this paper is extremely small, and it is not the focus of this paper and can be ignored.

Overall, the geological structure of Shanghai area is mainly dominated by the soft soil layer, and the soft soil layer has a relatively large impact on engineering construction, which is also a main reason that the Shanghai area is prone to subsidence.

\subsection{Correlation Analysis between Surface Subsidence Time Series and Rainfall}

According to previous studies [41,42], urban rainfall and urban surface subsidence have a certain relationship. The greater the rainfall the more stable or somewhat uplift the land will be. The surface subsidence caused by groundwater exploitation is effectively alleviated because the increase in rainfall can replenish the groundwater content.

Shanghai is close to the ocean and is greatly affected by the ocean. Meanwhile, it is located in the subtropical monsoon climate. Thus, the precipitation times in Shanghai is longer, and the influence of rainfall on the change in groundwater level is greater.

In this paper, the monthly precipitation information of two meteorological stations QX1 and QX2, which are located in Baoshan and Longhua of Shanghai in 2019, respectively. They are selected from the National Meteorological Data Network. In order to better analyze the correlation between the time series of surface subsidence and rainfall, the subsidence data used in this section are the average values of the subsidence of PSs within $200 \mathrm{~m}$ around the weather station. In this experiment, a buffer zone of $200 \mathrm{~m}$ was established, with two weather stations as the center. The PSs within $200 \mathrm{~m}$ around the two weather stations were extracted separately, and the mean subsidence of these PSs were obtained as the basis for comparison.

The results of comparison between the two meteorological stations and the subsidence are shown in Figures 8 and 9. In the months with relatively more precipitation, the surface subsidence is significantly smaller or uplift, whereas in the months with relatively less precipitation, the surface subsidence is easy to occur significantly. 


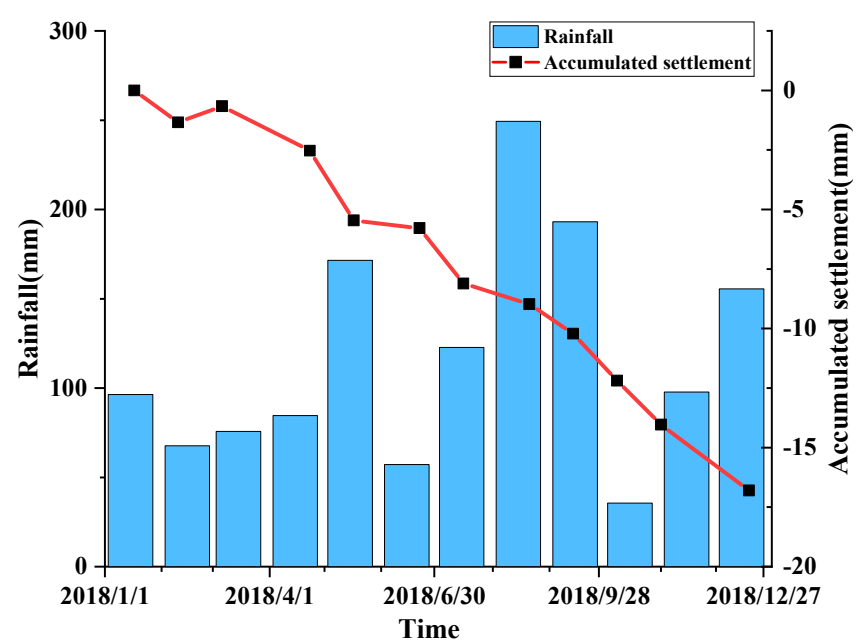

Figure 8. QX1Comparison of Precipitation and Subsidence of National Meteorological Station.

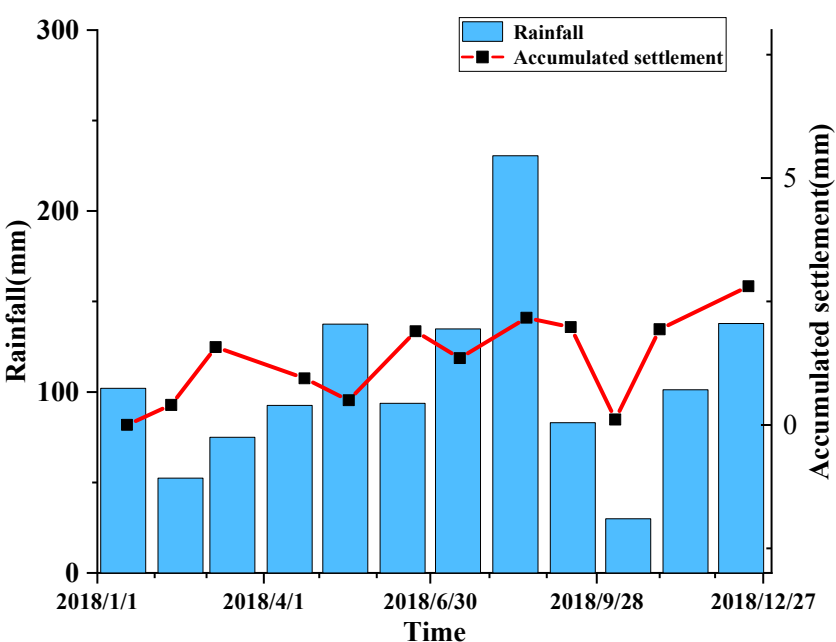

Figure 9. QX2 Comparison of Precipitation and Subsidence of National Meteorological Station.

The 2018 rainy season in the middle and lower reaches of the Yangtze River begins in June. The rainfall data of Shanghai area show that the rainfall in Shanghai has increased significantly since June. As shown in Figures 8 and 9, the subsidence amount of the subsidence feature points located in the QX1 region significantly decreased, whereas the subsidence feature points located in the QX2 region showed a small amplitude of uplift, thereby confirming the above inference.

The result shows that the seasonal variation of land subsidence is related to rainfall. We can combine the conclusion of linear relationship between subsidence and groundwater exploitation, which has been verified by previous studies. The over exploitation of groundwater will lead to surface subsidence, but the timely supplement of rainfall to groundwater will reduce the amount of subsidence effectively and can reduce the occurrence of excessive subsidence [43].

\subsection{Surface Subsidence and Groundwater Level Change}

The extraction/injection of subsurface resources (e.g., groundwater, natural gas, etc.) in the ground can directly affect the surface subsidence, while the surface subsidence can also reflect the subsurface resource content. Scholars have discovered that in the areas where the extraction of underground resources is more serious, the surface subsidence is more obvious, indicating that there exists a certain relationship between the exploitation of underground resources and the subsidence of the surface [44-46]. As a key city in China, Shanghai always has a serious problem of water exploitation. According to the 
"2018 Shanghai Water Resources Bulletin" and "2019 Shanghai Water Resources Bulletin" published by Shanghai Municipal Water Bureau, Shanghai's water resources in 2018 and 2019 are shown in Table 3. For nine consecutive years, the amount of artificial recharge in Shanghai is far greater than the amount of mining, which is also the fundamental reason for the stability of subsidence in most areas of Shanghai.

Table 3. Overview of water resources in Shanghai in 2018 and 2019.

\begin{tabular}{ccc}
\hline Parameters $\mathbf{( m}^{\mathbf{3}} \mathbf{)}$ & $\mathbf{2 0 1 8}$ & $\mathbf{2 0 1 9}$ \\
\hline per capita water consumption & 313 & 314 \\
Annual surface runoff & $76.17 \times 108$ & $75.96 \times 108$ \\
Groundwater withdrawals & $2 \times 106$ & $1 \times 106$ \\
Industrial water & $34.41 \times 108$ & $34.02 \times 108$ \\
Domestic water & $13.26 \times 108$ & $13.5 \times 108$ \\
Recharge groundwater & $21.07 \times 106$ & $20.14 \times 106$ \\
\hline
\end{tabular}

To further study the groundwater level changes and the relationship between the surface subsidence, this paper obtained the distribution in Songjiang district, Jinshan district, and Fengxian in four water level monitoring well data. Compared with the average subsidence in the surrounding 200-m area, the distribution of groundwater level monitoring wells is shown in Figure 3, and the comparison result is shown in Figure 10. The specific analysis is detailed as follows: monitoring wells A and B are located near Songjiang Erzhong, East Zhongshan Road, Songjiang District, and near Tinglin Vocational School, Songjin Road, Jinshan District; monitoring wells C and D are located near Caojing Chemical Plant, Huhang Road, Jinshan District, and near Zhujia Village, Qianqiao Town, Fengxian District.
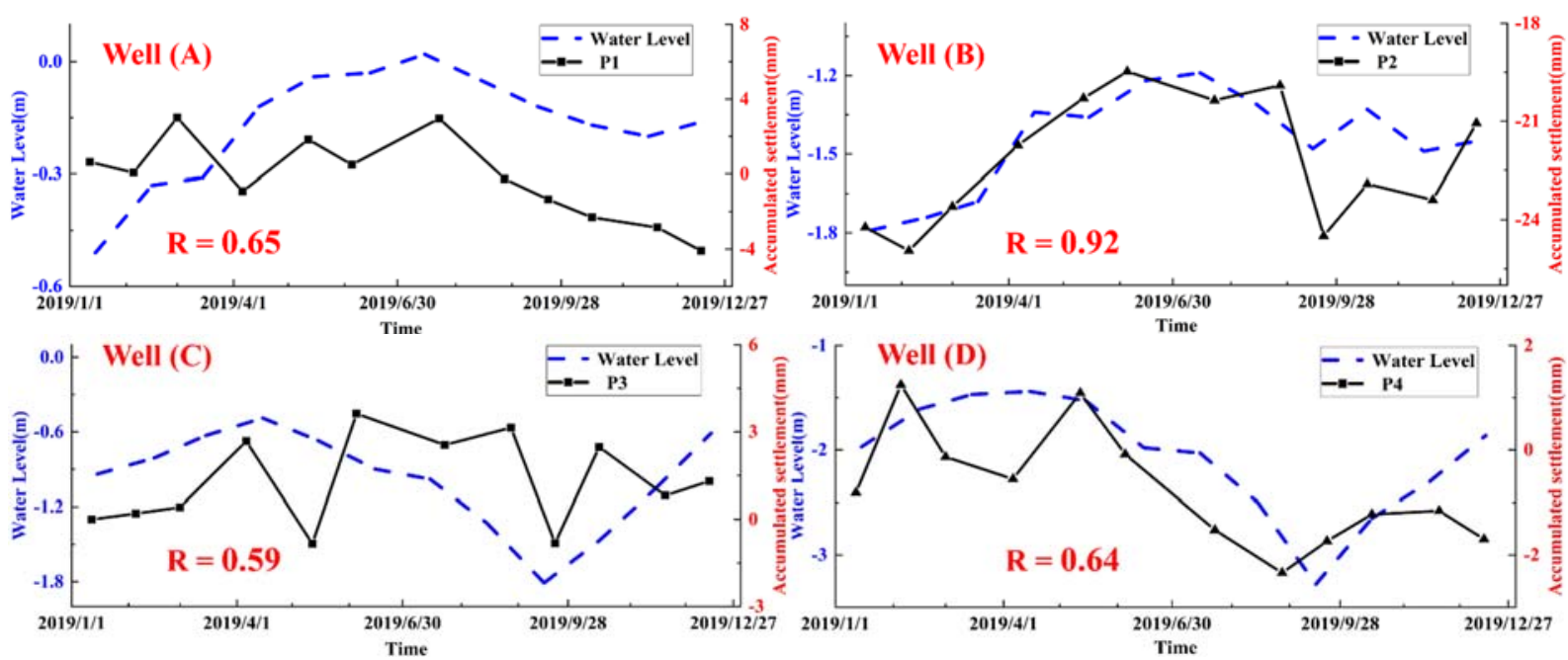

Figure 10. Time series of surface deformation and groundwater level change at multiple observation points.

The gray correlation analysis method was used to compare the P1-P4 accumulated subsidence curve with the groundwater level change curve. The grey correlation degree was obtained as: $0.65,0.92,0.59,0.64$, thereby showing high consistency $[47,48]$. When the groundwater level rises, the subsidence of the surface detection points tends to be stable or rises to some extent. Meanwhile, when the local water level decreases obviously, the subsidence of the surface detection points also occurs obviously. In July 2019, the rainy season gradually receded in the lower reaches of the Yangtze River, and the rainfall decreased significantly, thereby decreasing the groundwater level at the monitoring wells significantly. At the same time, P1-P4 experienced significant subsidence to varying 
degrees, thereby verifying the correlation between the groundwater level and the surface subsidence [49-53].

\subsection{Surface Subsidence and Underground Rail Transit Construction}

Subway has now become an important means of transportation in people's daily lives. As of August 2020, Shanghai Metro has 17 operating lines (including maglev lines), 416 stations (including 2 maglev lines), and a total mileage of $705 \mathrm{~km}$ (including $29 \mathrm{~km}$ maglev lines). At the same time, four rail transit lines are under construction in Shanghai. Given the factors of geological soft soil in Shanghai, the construction of underground rail lines are greatly affected by geology, and abnormal subsidence occurs from time to time. Therefore, it is particularly necessary to monitor the subsidence of the rail transit lines that are under construction and their surrounding areas [54-56].

The construction of Shanghai Metro Line 15 was started in August 2016 and the whole line was opened in December 2019, with underground stations. In the time span of this experimental study, the line is in the period of accelerated construction and natural consolidation of the ground, so it is of great engineering significance to monitor its subsidence, and the study on the correlation between surface subsidence and underground rail transit construction is the representative of Shanghai Metro Line 15.

In this section, Shanghai Metro Line 15 is selected as the research object, and the subsidence field is extracted from the line and the surrounding area within $600 \mathrm{~m}$. In 2016, the construction of Shanghai Metro Line 15 began, and in December 2019, the whole line was successfully completed. The total length of Line 15 is $42.3 \mathrm{~km}$ with 30 stations, all of which are underground stations.

According to the monitoring of this line and its surrounding areas (the subsidence rate figure is shown in Figure 11), two obvious subsidence areas of A and B are found in Metro Line 15 (Respectively shown in a and b in Figure 11). Area a is located in Minhang District, in the south of Route 15, including Zizhu High-tech Zone Station to Jingxi Road Station. The accumulated subsidence of Area a is shown in Figure 12. Two obvious subsidence funnel areas are found on the subsidence trend line. By comparing Figure 11, the two places are the area of Yongde Road Station and the area between Yuanjiang Road Station and Shuangbai Road Station. The maximum accumulated subsidence of the two places is $-40.2 \mathrm{~mm}$ and $-37.8 \mathrm{~mm}$ respectively. Area $\mathrm{b}$ is located in Changning District, Shanghai, and includes Yaohong Road Station to Guilin Road Station. The subsidence of different degrees appeared in this area, and the subsidence near Wuzhong Road Station was the most obvious, with the maximum accumulated subsidence of $-28.9 \mathrm{~mm}$. In December 2019, the two underground construction lines of Metro Line 15 converged on the Guilin Station. The intersection of the two construction lines greatly increases the bearing capacity of the ground, which is the main reason for the obvious subsidence of the area $[57,58]$. After the completion of the subway, the natural consolidation subsidence becomes the main reason for the subsidence of Areas a and $b[59,60]$.

In Zizhu high-tech area standing nearby, the subsidence phenomenon is more evident. The area of Minxing District of Shanghai Zizhu science park situates many universities and scientific research bases to gather hereat. Residents' living water all come from the exploitation of groundwater, and the consolidation subsidence caused by subway construction becomes the settling of the main reasons. 


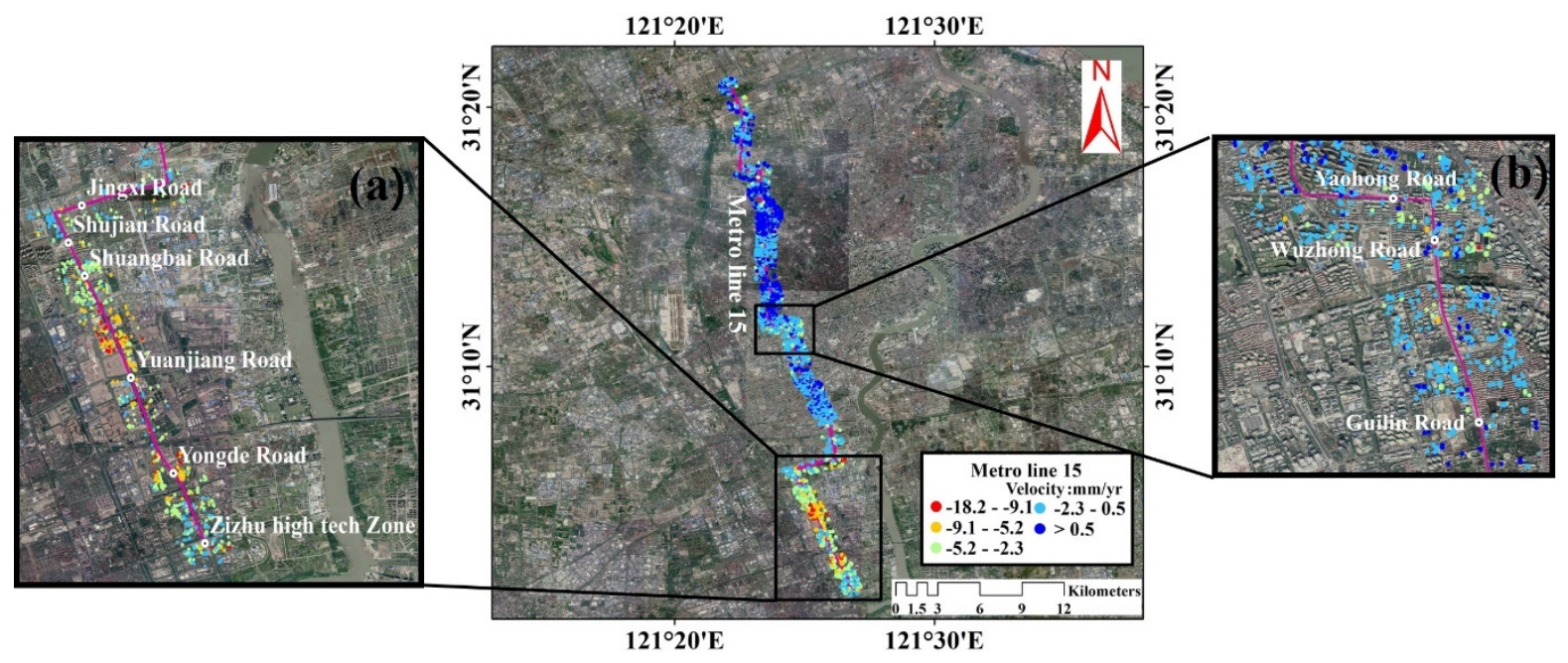

Figure 11. Subsidence rate map of metro line 15 and its surrounding area. Area A and Area B are shown in (a,b) respectively.

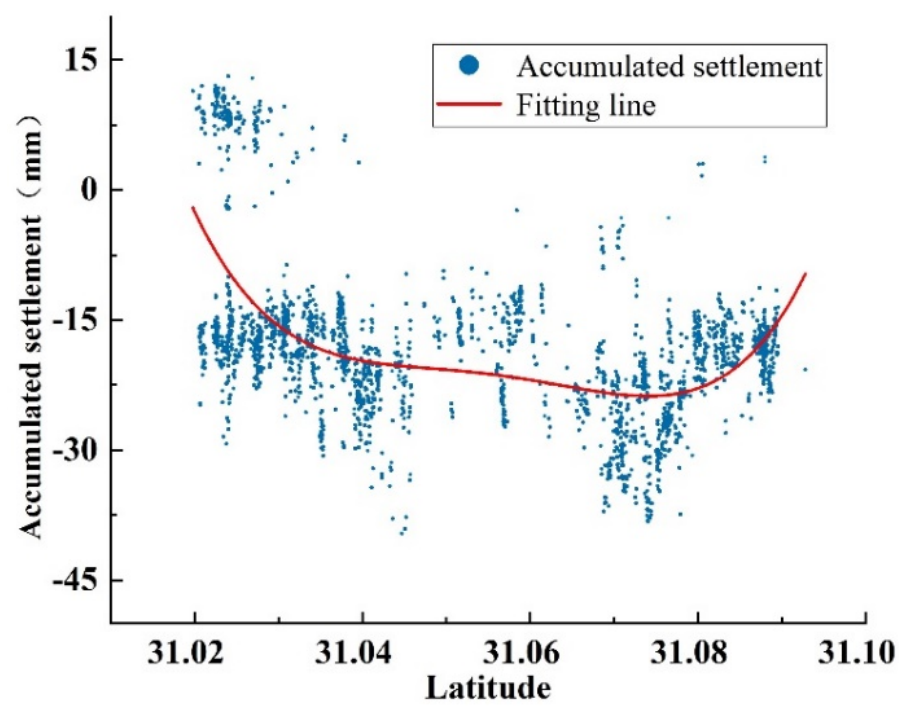

Figure 12. Cumulative subsidence of area A.

\subsection{Influence of Industrialization Development on Land Surface Subsidence}

In this section, feature region $C$ in Figure 4 is selected for specific analysis. Area $C$ is located in the south of Fengxian District, Shanghai. It is the gathering place of Fengxian District Industrial Area, where many large industrial plants are located.

Figure 13 shows the deformation rate diagram in the characteristic area, and the three-dimensional accumulated subsidence diagram is shown in Figure 14. As shown in Figure 13, obvious subsidence occurs in area $\mathrm{C}$, and the subsidence rate in many areas exceeds $-20 \mathrm{~mm} /$ year. Among them, GY-a area is located near the intersection of Fengzhe Road and Zhenqian Road in Fengxian District with the maximum accumulated subsidence of $-54 \mathrm{~mm}$. A number of large industrial plants, such as Rubber \& Plastic Products Co., Ltd., Thermal Energy Equipment Co., Ltd., are clustered in this area. By comparison with Figure 14, an obvious subsidence funnel in this area is observed. GY-b area is located in Xinghuo Development Industrial Zone, Fengxian District, where the subsidence phenomenon is more serious, with the maximum accumulated subsidence of $-75 \mathrm{~mm} /$ year. 


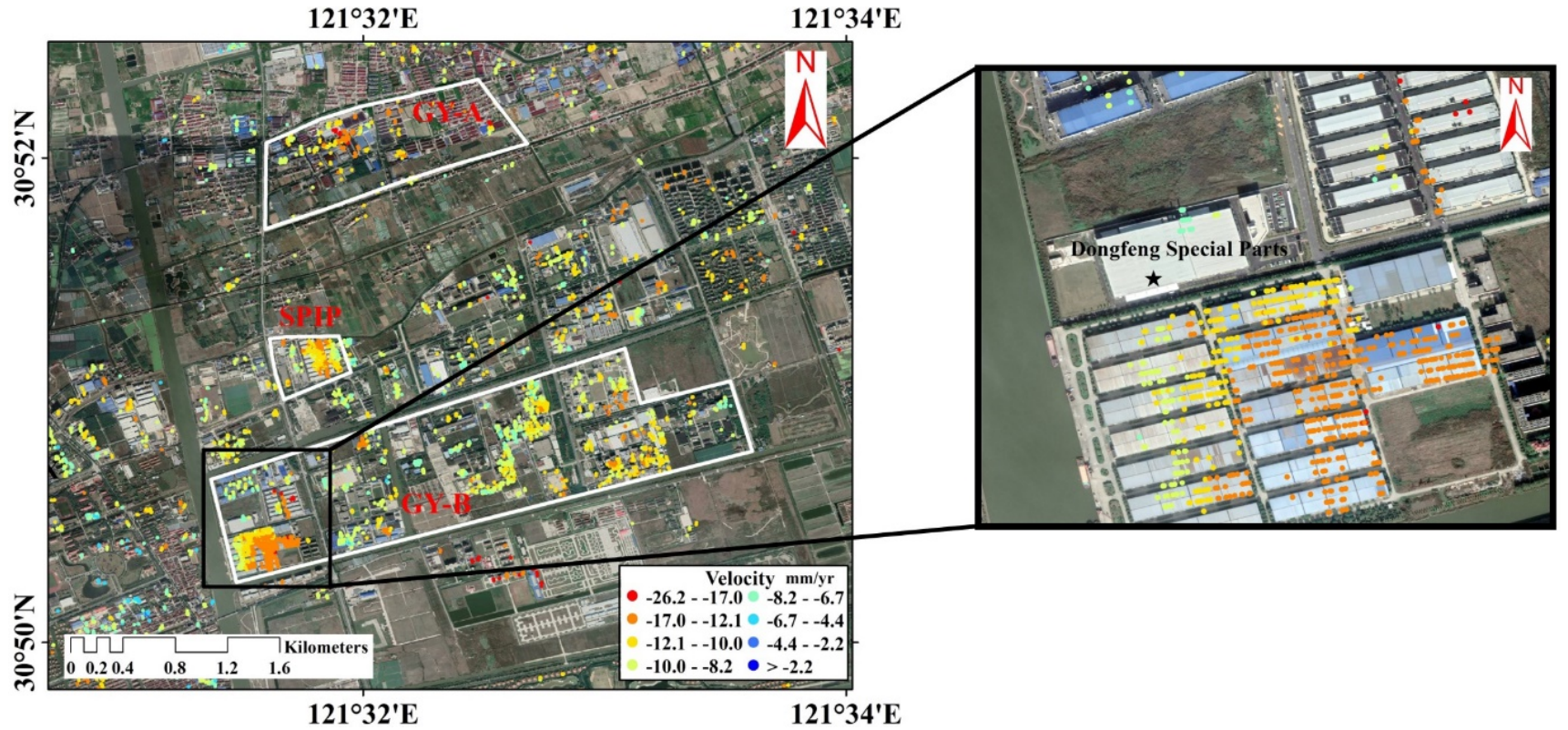

Figure 13. Characteristic area shape rate chart.

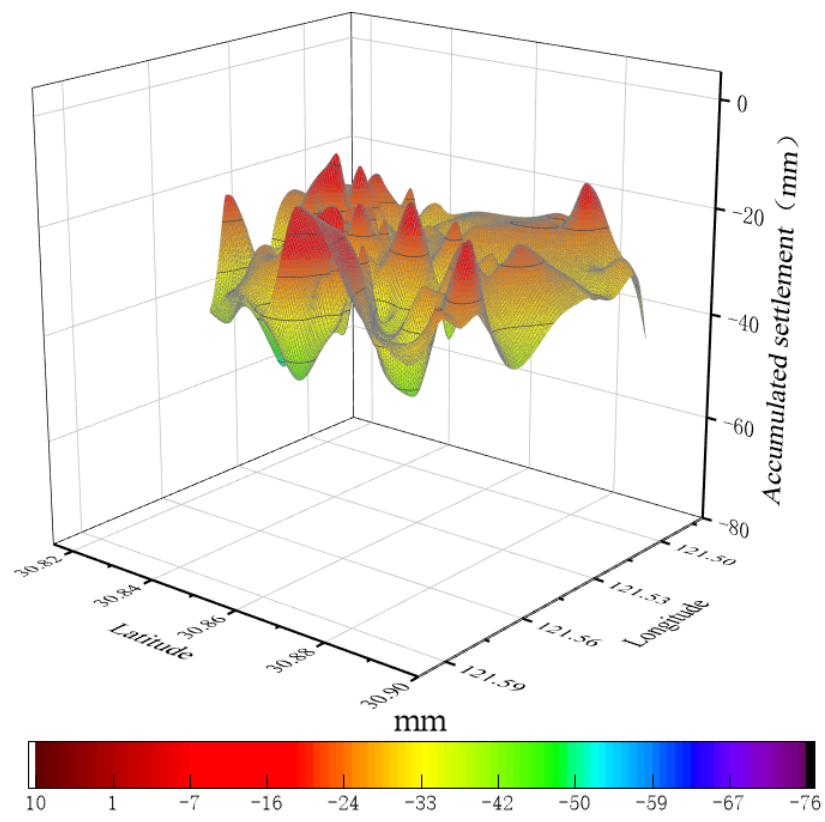

Figure 14. 3D accumulative subsidence map of characteristic area.

This area is the spark industrial area, gathered Jinfengyuan Paper Co., Ltd., Yadong Petrochemical and other large factories and heavy and light industrial bases.

The area with the most serious subsidence, as shown in the right part of Figure 13, is near Dongfeng Automobile Special Parts Co., Ltd. SPIP area is Shanghai Paimilei Industrial Park, which has a number of heavy industrial bases. And Figure 15 shows the change of water level at the water level monitoring well D near the feature area in 2019. Compared with other areas of Shanghai, the groundwater level in this area is significantly lower because of the over-exploitation of groundwater by industrial production in this area. Overall, the overexploitation of groundwater caused by industrial development is the main cause of surface subsidence in the three industrial areas. 


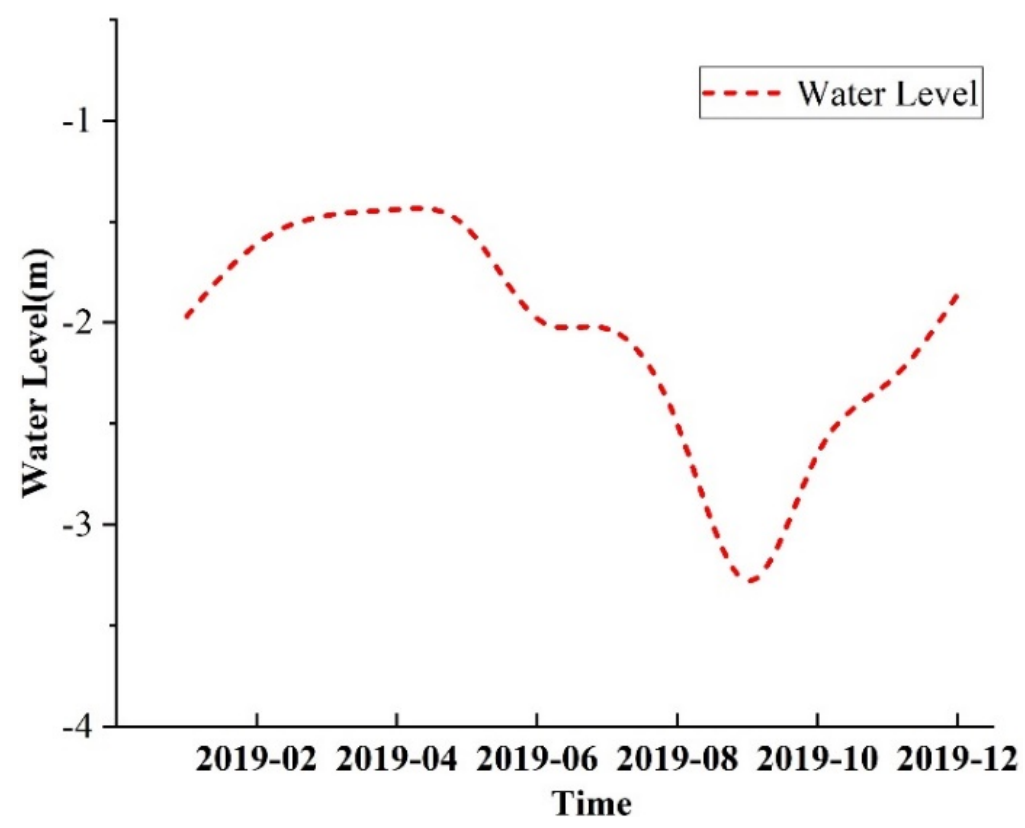

Figure 15. Water level change of water level monitoring point D in 2019.

\subsection{Surface Subsidence and Urbanization Development}

In recent years, with the rapid development of thermal infrared remote sensing, many countries have launched noctilucent remote sensing satellites.

Nighttime light remote sensing refers to the use of remote sensing technique to capture the light distribution on the earth at night, which can effectively reflect the spatial distribution of human activities, so it is often used for remote sensing inversion of urban development [61-63].

In this paper, VIIRS noctilucent remote sensing satellite sensor was used to obtain the noctilucent remote sensing data of the main urban area of Shanghai, and the difference processing of the nighttime light imageries was carried out to obtain the urbanization development changes in Shanghai from April 2018 to April 2020. Due to the poor imaging effect of the monthly composite data from January 2018 to March 2018 published by VIIRS, this paper selected the monthly composite products from April 2018 and April 2020 published by VIIRS, as shown in Figures 16 and 17. After the difference processing, the change in nighttime light imageries in Shanghai from April 2018 to April 2020 is obtained in this paper (Figure 18). The overall trend of urbanization in Shanghai is developing rapidly. Among them, it is located in the southeast of Shanghai Jinshan District and the southern cross of light brightness rising big scope, which reflect regional urbanization and the development of infrastructure construction. At the same time, compared with Figure 4, the subsidence of this area has a high correlation with the change in light brightness. This finding also proves that the process of urbanization and infrastructure construction will further increase the pressure on the surface, thereby resulting in uneven subsidence. The results show that urbanization and infrastructure construction are positively correlated with surface subsidence to a certain extent. 


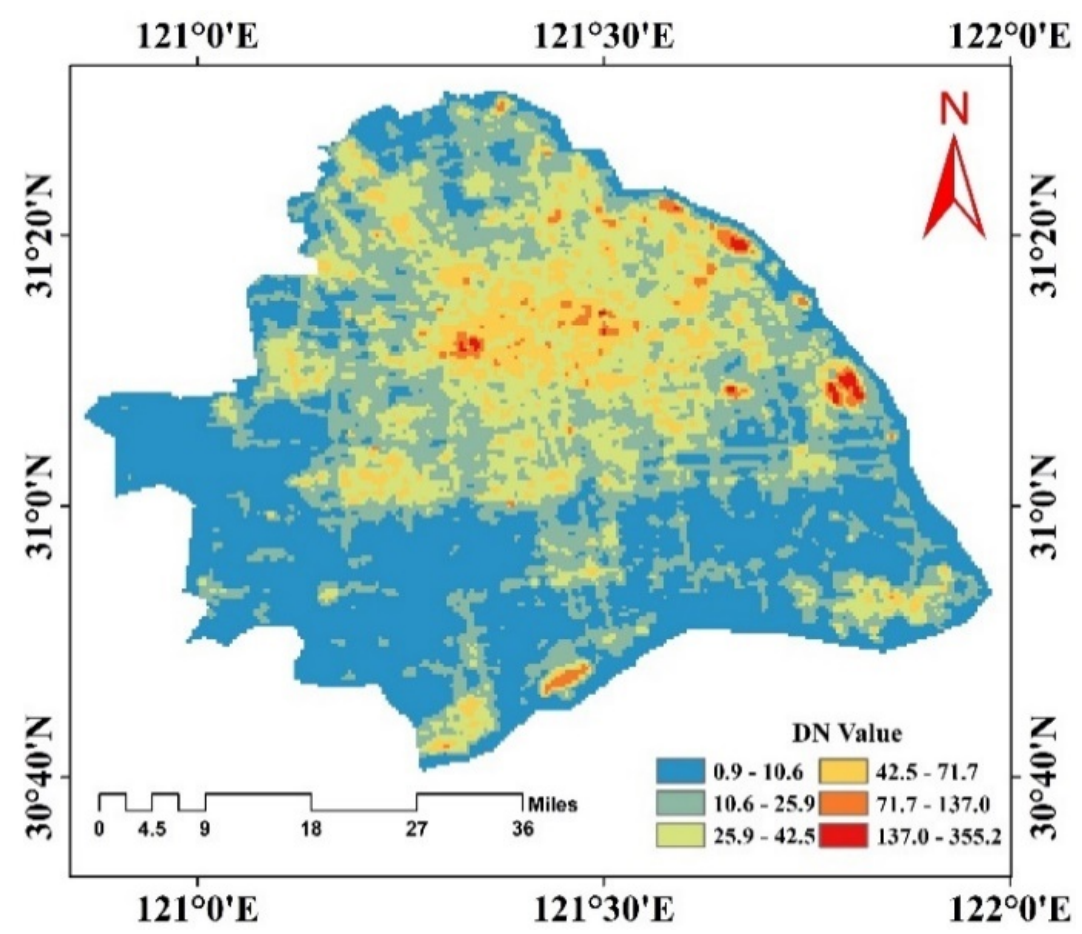

Figure 16. Night lighting data of main urban area of April 2018.

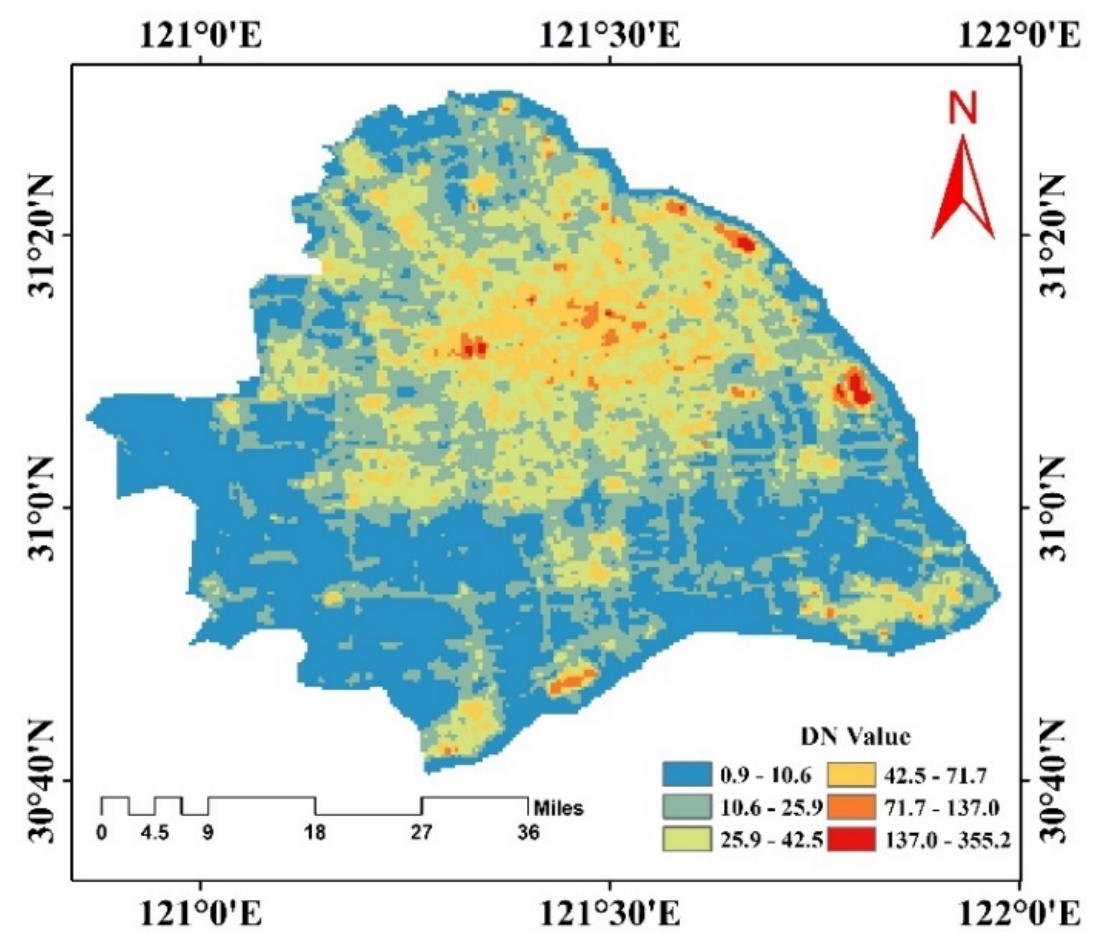

Figure 17. Night lighting data of main urban area of Shanghai in Shanghai in April 2020. 


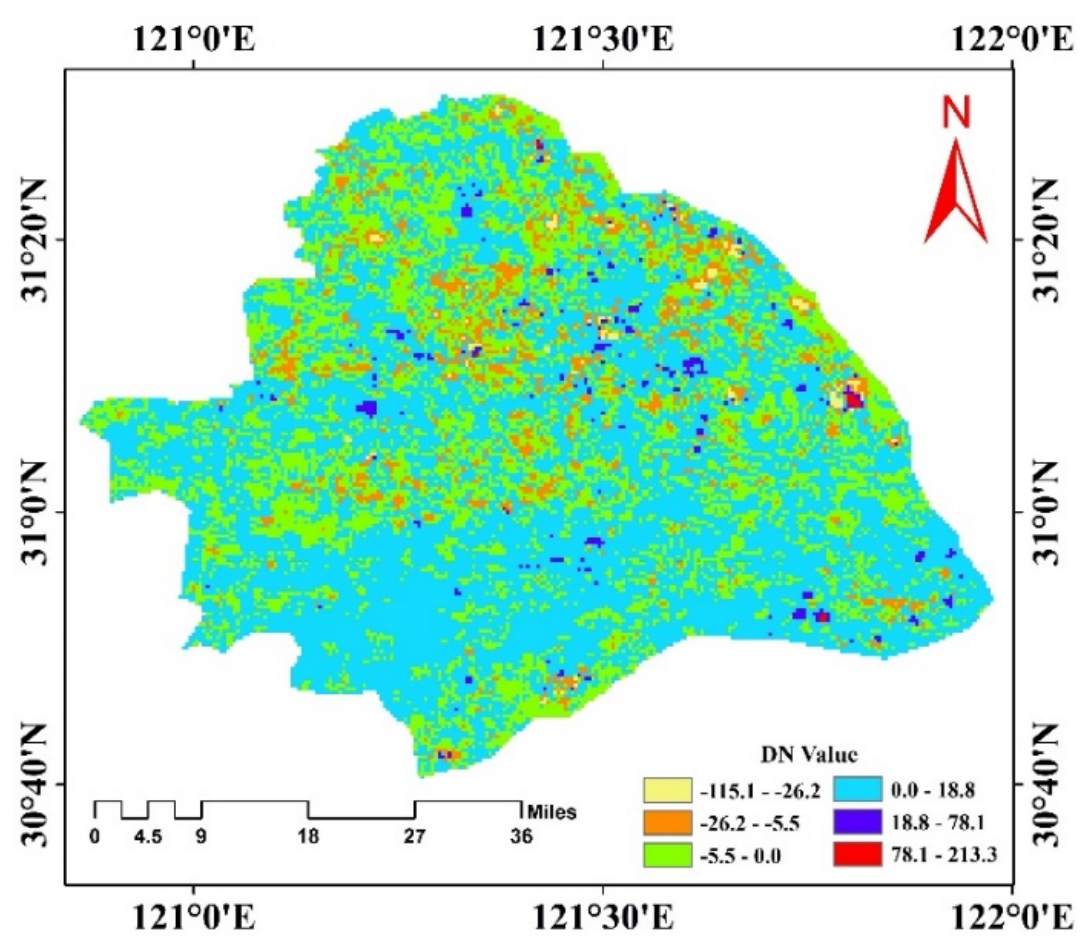

Figure 18. Difference chart of night light data of Shanghai main urban area in 2020 and 2018.

\section{Conclusions}

In view of the lack of large-scale subsidence research, insufficient analysis of subsidence mechanism and low timeliness of experimental data in Shanghai. In this paper, time-series InSAR technique was used to process the 36 Sentinel-1A SAR images from January 2018 to March 2020. Combined with the changes in precipitation, groundwater level, and urbanization process in Shanghai, the spatial-temporal characteristics of surface subsidence in Shanghai are analyzed in detail. The main conclusions are presented as follows:

(1) The internal coincidence accuracy of PSInSAR technique is analyzed. Most PS point standard deviations are less than $1 \mathrm{~mm} /$ year, which is relatively small. Therefore, the accuracy and stability of PSInSAR technique for surface subsidence monitoring in Shanghai area are relatively high.

(2) The uneven subsidence in Shanghai is obvious. The surface subsidence in the north and east of Shanghai is stable, and the surface subsidence in some areas is uplifted. However, the subsidence in Songiiang District in the east, Jinshan District in the south and Fengxian District in Shanghai are more serious, with large area subsidence and outward expansion trend. The subsidence near Xinghuocun in Fengxian District is the most serious, with the maximum accumulated subsidence of $-75 \mathrm{~mm}$, which is related to the exploitation of groundwater caused by industrial water in this area.

(3) The study area is mainly a soft soil geological area, and the water content of soft soil is relatively high, which has a relatively large impact on engineering construction. This reason is the main cause that Shanghai area is prone to subsidence. In addition, seasonal changes in surface subsidence may be closely related to rainfall, and timely replenishment of groundwater by rainfall can reduce the subsidence effectively and slow down the occurrence of excessive subsidence. The surface subsidence in the study area is highly correlated with the change in groundwater level. That is, when the groundwater level rises, the surface will be uplifted or stable, and when the water level drops, the surface will obviously sink.

(4) Three subsidence areas were identified along the Shanghai Metro Line 15, which are the area of Yongde Road Station, the area between Yuanjiang Road Station and 
Shuangbai Road Station, and the area between Yaohong Road Station and Guilin Road Station. Among them, the subsidence of Yongde Road Station is the most serious with a maximum accumulated subsidence that reaches $-40.2 \mathrm{~mm}$. The main reason for the subsidence is the natural consolidation subsidence of the surface after the completion of the subway construction. Additionally, the industrial water in large industrial zones in Shanghai area increases the amount of underground water extraction, which is the main reason for the subsidence of industrial areas. Urbanization and infrastructure construction are also highly correlated with surface subsidence to a certain extent.

Author Contributions: All authors contributed to the manuscript and discussed the results. J.L. and L.Z. put forward the idea of this paper. J.L. processed and analyzed the sentinel data and contributed to the manuscript of the paper. L.Z. made criticism and revised the manuscript. C.R. analyzed the relationship between rainfall and ground subsidence. L.L. analyzes the results of PSInSAR. D.Z. analyzed the settlement of the metro line, and made critical comments on the manuscript. J.M. analyzed the settlement of the industrial areas, and made critical comments on the manuscript. Y.S. processes and analyzes the NPP-VIIRS data. All authors have read and agreed to the published version of the manuscript.

Funding: This work was supported by the Guangxi Science and Technology Plan Project, grant number GUIKE AD19110107; the Natural Science Foundation of Guangxi, grant number 2018GXNSFBA050006; the Wuhan Science and Technology Plan Project, grant number 2019010702011314; the National Natural Science Foundation of China, grant numbers 42064003 and 42064002; Guangxi Universities Young and Middle-aged Teachers' Basic Scientific Research Ability Improvement Project, grant number 2020KY06032; and the Foundation of Guilin University of Technology, grant number GUTQDJJ2018036.

Institutional Review Board Statement: Not applicable.

Informed Consent Statement: Not applicable.

Data Availability Statement: Data incorporated in this research is available free through the these webpages: Sentinel-1A (https:/ / scihub.copernicus.eu/dhus/\#/home, 20 May 2020), SRTM DEM (http:/ / srtm.csi.cgiar.org/srtmdata, 2 June 2020), satellite precise orbit data (https:/ /qc.sentinel1.eo. esa.int/aux_poeorb, 22 June 2020), rainfall data (http: / / data.cma.cn, 1 July 2020), groundwater level data (http:/ / data.sigs.cn, 20 July 2020), NPP-VIIRS data (https:/ /ngdc.noaa.gov/eog/download. html, 20 July 2020).

Acknowledgments: Thanks to the Sentinel-1A image and satellite precise orbit data provided by ESA, SRTM DEM data provided by NASA, rainfall data provided by China National Meteorological Science Data Center, groundwater level data provided by the Shanghai Geological Data Information Sharing Platform and NPP-VIIRS data provided by NOAA. And the Anonymous Reviewers of Applied Sciences for their thorough review, and their instructive comments and suggestions.

Conflicts of Interest: The authors declare no conflict of interest.

\section{References}

1. Qin, W.; Huang, Q.Y.; Yu, L.; Hu, B.Q. Surface subsidence monitoring during the construction of Nanning subways. J. Geo-Inf. Sci. 2019, 21, 1467-1478.

2. Bai, Z.C.; Jin, G.W.; Zhang, H.M.; Xu, Q.; Hu, J.B.; Wang, B.C. Subsidence monitoring of tianjin using PSInSAR technique with sentinel-1A. J. Geomat. Sci. Technol. 2017, 34, 283-288.

3. Zhao, C.Y.; Zhang, Q.; Ding, X.L.; Lu, Z.; Yang, C.S.; Qi, X.M. Monitoring of land subsidence and ground fissures in Xi'an, China 2005-2006 mapped by SAR interferometry. Environ. Geol. 2009, 58, 147-150. [CrossRef]

4. Zhou, L.; Guo, J.M.; Li, X.; Hu, J.Y. Monitoring and analyzing on ground subsidence in Beijing area based on SBAS-InSAR. J. Geod. Geodyn. 2016, 36, 793-797.

5. Liu, Q.; Yue, G.S.; Ding, X.B.; Yuan, K.; Feng, G.C.; Xiong, Z.Q. Temporal and spatial characteristics analysis of Deformation along Foshan subway using time series InSAR. Geomat. Inf. Sci. Wuhan Univ. 2019, 44, 1099-1106.

6. Poland, M.; Burgmann, R.; Dzurisin, D.; Lisowski, M.; Masterlark, T.; Owen, S.; Fink, J. Constraints on the mechanism of long-term, steady subsidence at Medicine Lake volcano, northern California, from GPS, leveling, and InSAR. J. Volcanol. Geotherm. Res. 2006, 150, 55-78. [CrossRef]

7. Ruiz-Constán, A.; Ruiz-Armenteros, A.M.; Lamas-Fernández, F.; Martos-Rosillo, S.; Delgado, J.M.; Bekaer, D.P.S.; Sousa, J.J.; Gil, A.J.; Cuenca, M.C.; Hanssen, R.F.; et al. Multi-temporal InSAR evidence of ground subsidence induced by groundwater withdraw the Montellano aquifer. Environ. Earth Sci. 2016, 75, 242-258. [CrossRef] 
8. Gao, E.T.; Fan, D.L.; Fu, B.L.; Yong, Q.; Lan, Y.P. Land subsidence monitoring of Nanjing area based on PS-InSAR and SBAS technology. J. Geod. Geodyn. 2019, 39, 158-163.

9. Wang, H.Q.; Feng, G.C.; Xu, B.; Yu, Y.P.; Li, Z.W.; Du, Y.A.; Zhu, J.J. Deriving spatio-temporal development of ground subsidence due to subway construction and operation in delta regions with PS-InSAR data: A case study in Guangzhou, China. Remote Sens. 2017, 9, 1004. [CrossRef]

10. Dong, S.C.; Yin, H.W.; Yao, S.P.; Zhang, F. Detecting surface subsidence in coal mining area based on D-InSAR technique. J. Earth Sci. 2013, 24, 449-456. [CrossRef]

11. Chang, H.C.; Ge, L.L.; Rizos, C. DInSAR for mine subsidence monitoring using multi-source satellite SAR images. Photogramm. Eng. Remote Sens. 2005, 3, 1742-1745.

12. Du, Z.Y.; Ge, L.L.; Ng, A.H.M.; Li, X.J. Investigation on mining subsidence over Appin-West Cliff Colliery using time-series SAR interferometry. Int. J. Remote Sens. 2018, 39, 1528-1547. [CrossRef]

13. Chen, Y.; Zhang, K.F.; Tan, K.; Feng, X.J.; Li, H.Z. Long-term subsidence in lava fields at piton de la Fournaise Volcano measured by InSAR: New insights for interpretation of the eastern flank motion. Remote Sens. 2018, 10, 597. [CrossRef]

14. Bru, G.; Gonzalez, P.J.; Mateos, R.M.; Roldan, F.J; Herrera, G.; Bejar-Pizarro, M.; Fernandez, J. A-DInSAR monitoring of landslide and subsidence activity: A case of urban damage in Arcos de la Frontera, Spain. Remote Sens. 2017, 9, 787. [CrossRef]

15. Atzori, S.; Hunstad, I.; Chini, M.; Salvi, S.; Tolomei, C.; Bignami, C.; Stramondo, S.; Trasatti, E.; Antonioli, A.; Boschi, E. Finite fault inversion of DInSAR coseismic displacement of the 2009 L'Aquila earthquake (central Italy). Geophys. Res. Lett. 2009, 36, L15305. [CrossRef]

16. Scaioni, M.; Marsella, M.; Crosetto, M.; Tornatore, V.; Wang, J. Geodetic and remote-sensing sensors for dam deformation monitoring. Sensors 2018, 18, 3682. [CrossRef] [PubMed]

17. Gabriel, A.K.; Goldstein, R.M.; Zebker, H.A. Mapping small elevation changes over large areas: Differential radar interferometry. J. Geophys. Res. Solid Earth 1989, 94, 9183-9191. [CrossRef]

18. Ferretti, A.; Prati, C.; Rocca, F. Permanent scatterers in SAR interferometry. IEEE Trans. Geosci. Remote Sens. 2001, 39, 8-20. [CrossRef]

19. Beradino, P.; Fornaro, G.; Lanari, R.; Sansosti, E. A new algorithm for surface deformation monitoring based on small baseline differential SAR interferograms. IEEE Trans. Geosci. Remote Sens. 2002, 40, 2375-2383. [CrossRef]

20. Zhu, X.X.; Chen, M.; Gong, H.L.; Li, X.J.; Yu, J.; Zhu, L.; Zhou, Y.Y.; Li, Y. The Subsidence Monitoring along Beijing Subway Network Based on MT-InSAR. J. Geo-Inf. Sci. 2018, 20, 1810-1819.

21. Chen, H. Surface Subsidence Monitoring in Mining Area Based on TCP-InSAR Technology; China University of Mining and Technology: Xuzhou, China, 2016.

22. Caló, F.; Notti, D.; Galve, J.P.; Abdikan, S.; Gorum, T.; Pepe, A.; Sanli, F.B. DInSAR-Based detection of land subsidence and correlation with groundwater depletion in Konya Plain, Turkey. Remote Sens. 2017, 9, 83. [CrossRef]

23. Zhou, L.; Guo, J.M.; Hu, J.Y.; Li, J.W.; Xu, Y.F.; Pan, Y.J.; Shi, M. Wuhan surface subsidence analysis in 2015-2016 based on sentinel-1A data by SBAS-InSAR. Remote Sens. 2017, 9, 982. [CrossRef]

24. Brunori, C.A.; Bignami, C.; Albano, M.; Zucca, F.; Samsonov, S.; Groppelli, G.; Norini, G.; Saroli, M.; Stramondo, S. Land subsidence, ground fissures and buried faults: InSAR monitoring of Ciudad Guzman (Jalisco, Mexico). Remote Sens. 2015, 7, 8610-8630. [CrossRef]

25. Yang, M.S.; Yang, T.L.; Zhang, L.; Lin, J.X.; Qin, X.Q.; Liao, M.S. Spatio-temporal characterization of a reclamation subsidence in the Shanghai coastal area with time series analyses of X-, C-, and L-band SAR datasets. Remote Sens. 2018, 10, 329. [CrossRef]

26. Wang, R.; Yang, T.L.; Yang, M.S.; Liao, M.S.; Lin, J.X. A safety analysis of elevated highways in Shanghai linked to dynamic load using long-term time-series of InSAR stacks. Remote Sens. Lett. 2019, 10, 1133-1142. [CrossRef]

27. Zhang, L.N.; Wu, J.C.; Li, T.; Chen, J. Monitoring ground deformation based on small baseline approach in Shanghai. J. Tongji Univ. 2012, 40, 1564-1568.

28. Antonio, P.; Manuela, B.; Zhao, Q.; Yang, T.; Wang, H. The use of C-/X-band time-gapped SAR data and geotechnical models for the study of Shanghai's ocean-reclaimed lands through the SBAS-DInSAR technique. Remote Sens. 2016, 8, 911-929.

29. Yu, L.; Yang, T.L.; Zhao, Q.; Liu, M.; Pepe, A. The 2015-2016 ground displacements of the shanghai coastal area inferred from a combined COSMO-SkyMed/Sentinel-1 DInSAR analysis. Remote Sens. 2017, 9, 1194. [CrossRef]

30. Qin, X.Q.; Yang, T.L.; Yang, M.S.; Zhang, L.; Liao, M.S. Health diagnosis of major transportation infrastructures in Shanghai metropolis using high-resolution persistent scatterer interferometry. Sensors 2017, 17, 2770. [CrossRef]

31. Zhao, J.W.; Wu, J.C.; Ding, X.L.; Wang, M.Z. Elevation extraction and deformation monitoring by multitemporal InSAR of Lupu Bridge in Shanghai. Remote Sens. 2017, 9, 897. [CrossRef]

32. Zhou, C.D.; Gong, H.L.; Zhang, Y.Q.; Duan, G.Y. The influence of building load to land subsidence in Beijing plain based on PS-InSAR and GIS. J. Geo-Inf. Sci. 2016, 18, 1551-1562.

33. Pan, C.; Jiang, L.M.; Sun, Q.S.; Jiang, Y.N. Monitoring and Analyzing Chengdu Ground Subsidence Based on InSAR Technology by Using Sentinel-1 Radar Image. J. Geod. Geodyn. 2020, 40, 198-203.

34. Zhang, Z.J.; Wang, C.; Wang, M.M.; Wang, Z.W.; Zhang, H. Surface deformation monitoring in Zhengzhou city from 2014 to 2016 using time-series InSAR. Remote Sens. 2018, 10, 1731. [CrossRef]

35. Li, D.R.; Liao, M.S.; Wang, Y. Progress of permanent scatterer interferometry. Geomat. Inf. Sci. Wuhan Univ. 2004, $29,10-24$.

36. Liao, M.S. Subsidence monitoring in Shanghai using the PSInSAR technique. Shanghai Land Resour. 2012, 33, 5-10. 
37. Wu, H.W.; Li, Q.; Liu, G.B. Characteristics of one-dimensional compressibility of Shanghai clay. Chin. J. Geotech. Eng. 2011, 33, 630-636.

38. He, P.; Wang, W.D.; Xu, Z.H. Empirical correlations of compression index and swelling index for Shanghai clay. Rock Soil Mech. 2018, 39, 3773-3782.

39. Gao, G.Y.; Chen, Q.S.; He, J.F.; Zhang, X.L. Effect of rise of groundwater table on seismic ground response of soft soil in Shanghai. Chin. J. Geotech. Eng. 2011, 33, 989-995.

40. Xu, S.; Chen, Y.L.; Zhao, C.X. One-dimensional consolidation tests of creep deformation and secondary consolidation charhcteristics of soft soils in Shanghai area. J. Eng. Geol. 2008, 16, 65-71.

41. Shi, M.; Gong, H.L.; Gao, M.L.; Chen, B.B.; Zhang, S.K.; Zhou, C.F. Recent ground subsidence in the North China Plain, China, revealed by sentinel-1A datasets. Remote Sens. 2020, 12, 3579. [CrossRef]

42. Rateb, A.; Hermas, E. The 2018 long rainy season in Kenya: Hydrological changes and correlated land subsidence. Remote Sens. 2020, 12, 1390. [CrossRef]

43. Wasowski, J.; Pisano, L. Long-term InSAR, borehole inclinometer, and rainfall records provide insight into the mechanism and activity patterns of an extremely slow urbanized landslide. Landslides 2020, 17, 445-457. [CrossRef]

44. Benetatos, C.; Codegone, G.; Ferraro, C.; Mantegazzi, A.; Rocca, V.; Tango, G.; Trillo, F. Multidisciplinary analysis of ground movements: An underground gas storage case study. Remote Sens. 2020, 12, 3487. [CrossRef]

45. Settari, A.; Walters, D.A.; Stright, D.H.; Aziz, K. Numerical techniques used for predicting subsidence due to gas extraction in the North Adriatic Sea. Pet. Sci. Technol. 2008, 26, 1205-1223. [CrossRef]

46. Rutqvist, J.; Vasco, D.W.; Myer, L.R. Coupled reservoir-geomechanical analysis of $\mathrm{CO}_{2}$ injection and ground deformations at In Salah, Algeria. Greenh. Gas Control 2010, 4, 225-230. [CrossRef]

47. Du, J.C.; Kuo, M.F. Grey relational-regression analysis for hot mix asphalt design. Constr. Build. Mater. 2011, 25, 2627-2634. [CrossRef]

48. Deng, J. To analyze the connotation and extension (C\&E) of grey theory. J. Grey Syst. 2012, 24, $293-298$.

49. Ge, D.Q.; Yin, Y.P.; Wang, Y.; Zhang, L.; Guo, X.F.; Wang, Y. Seasonal subsidence-rebound and ground water level changes monitoring by using coherent target InSAR technique: A case study of Dezhou, Shandong. Remote Sens. Land Resour. 2014, 26, 103-109.

50. Huang, Y.H.; Lv, Y.J.; Zhou, Y.; Zhao, J.T.; Shi, B.X. A method for estimating land subsidence induced by ground water extraction and its application to site evaluation of Yizhuang light railway in Beijing. Rock Soil Mech. 2009, 30, 2458-2460.

51. Chen, B.B.; Gong, H.L.; Li, X.J.; Lei, K.C.; Wang, Y.B.; Wu, P.F. Relationship between load density and land subsidence of typical ground water funnel area of Beijing, China. J. Basic Sci. Eng. 2013, 21, 1046-1056.

52. Zhang, Y.D.; Wu, H.G.; Li, M.J.; Kang, Y.H.; Zhong, L. Investigating ground subsidence and the causes over the whole Jiangsu Province, China using sentinel-1 SAR data. Remote Sens. 2021, 13, 179. [CrossRef]

53. Aljammaz, A.; Sultan, M.; Izadi, M.; Abotalib, A.Z.; Elhebiry, M.S.; Emil, M.K.; Abdelmohsen, K.; Saleh, M.; Becker, R. Land subsidence induced by rapid urbanization in arid environments: A remote sensing-based investigation. Remote Sens. 2021, 13, 1109. [CrossRef]

54. Ma, X.X. Monitor the Impact of Beijing Subway Development on Land Subsidence Based on InSAR Technology; Capital Normal University: Beijing, China, 2013.

55. Ren, C.; Shi, X.J.; Zhou, L.; Huang, Y.L.; Liang, Y.J.; Zhu, Z.L. Land subsidence detection and analysis along subway based on sentinel-1A time series interferometry synthetic aperture radar. Sci. Technol. Eng. 2020, 20, 803-808.

56. Ge, D.Q.; Zhang, L.; Wang, Y.; Li, M.; Liu, B. Monitoring subsidence on Shanghai Metro line 10 during construction and operation using high-resolution InSAR. Shanghai Land Resour. 2014, 35, 62-67.

57. Meng, D.; Zang, X.G.; Yu, G.M.; Yuan, C.F. Comparative study of analytical methods for ground surface subsidence induced by subway station construction. Chin. J. Rock Mech. Eng. 2012, 31, 1169-1177.

58. Yao, X.D.; Wang, M.S. Statistic analysis of guideposts for ground subsidence induced by shallow tunnel construction. Chin. J. Rock Mech. Eng. 2006, 25, 2030-2035.

59. Yu, Q.; Yan, X.; Wang, Q.; Yang, T.; Lu, W.; Yao, M.; Dong, J.; Zhan, J.; Huang, X.; Niu, C.; et al. A spatial-scale evaluation of soil consolidation concerning land subsidence and integrated mechanism analysis at macro-, and micro-scale: A case study in Chongming East Shoal Reclamation Area, Shanghai, China. Remote Sens. 2021, 13, 2418. [CrossRef]

60. Miao, L.C.; Wang, F.; Lv, W.H. Ground surface subsidence due to urban tunnel construction. J. Southeast Univer. 2008, 38, $293-297$.

61. Zhu, H.; Zhang, Q.L.; Zhang, S. Spatial and temporal characteristics of socio-economic development in central Asia based on a series of nighttime light images from 1992 to 2017. J. Geo-Inf. Sci. 2020, 22, 1449-1462.

62. Li, X.; Ge, L.L.; Chen, X.L. Detecting Zimbabwe's decadal economic decline using nighttime light imagery. Remote Sens. 2013, 5, 4551-4570. [CrossRef]

63. Witmer, F.D.W.; O'Loughlin, J. Detecting the effects of wars in the Caucasus regions of Russia and Georgia using radiometrically normalized DMSP-OLS nighttime lights imagery. GISci. Remote Sens. 2011, 48, 478-500. [CrossRef] 